\title{
A B cell actomyosin arc network couples integrin co-stimulation to mechanical force-dependent immune synapse formation
}

Jia C. Wang ${ }^{1}$, Yang-In Yim ${ }^{1}$, Xufeng $W^{2}{ }^{2}$, Valentin Jaumouillé ${ }^{1}$, Andrew Cameron ${ }^{1}$, Clare M. Waterman ${ }^{1}$, John H. Kehrl ${ }^{3}$, and John A. Hammer ${ }^{1,4}$

${ }^{1}$ Cell and Developmental Biology Center, National Heart, Lung and Blood Institute, National Institutes of Health, Bethesda MD 20892

${ }^{2}$ Light Microscopy Core, National Heart, Lung and Blood Institute, National Institutes of Health, Bethesda MD 20892

${ }^{3} \mathrm{~B}$ Cell Molecular Immunology Section, National Institute of Allergy and Infectious Disease, National Institutes of Health, Bethesda MD 20892

${ }^{4}$ Author for correspondence: hammeri@nhlbi.nih.gov 


\begin{abstract}
B-cell activation and immune synapse (IS) formation with membrane-bound antigens are actin-dependent processes that scale positively with the strength of antigen-induced signals. Importantly, ligating the B-cell integrin, LFA-1, with ICAM-1 promotes IS formation when antigen is limiting. Whether the actin cytoskeleton plays a specific role in integrin-dependent IS formation is unknown. Here we show using superresolution imaging of mouse primary $B$ cells that LFA-1: ICAM-1 interactions promote the formation of an actomyosin network that dominates the B-cell IS. This network is created by the formin mDia1, organized into concentric, contractile arcs by myosin $2 \mathrm{~A}$, and flows inward at the same rate as B-cell receptor (BCR): antigen clusters. Consistently, individual BCR microclusters are swept inward by individual actomyosin arcs. Under conditions where integrin is required for synapse formation, inhibiting myosin impairs synapse formation, as evidenced by reduced antigen centralization, diminished BCR signaling, and defective signaling protein distribution at the synapse. Together, these results argue that a contractile actomyosin arc network plays a key role in the mechanism by which LFA-1 co-stimulation promotes B-cell activation and IS formation.
\end{abstract}




\section{Introduction}

$\mathrm{BCR}$ engagement with cognate antigen triggers striking changes in $\mathrm{B}$ cell physiology that promote B cell activation, immune synapse (IS) formation, and B cell effector functions (1-3). These changes include dramatic increases in actin filament assembly and dynamics that are thought to drive IS formation in B cells engaged with membrane-bound antigen (1-4). For B cells in vivo, this usually involves interactions with antigen bound to the surface of an antigen-presenting cell (APC) (4-6), although activating surfaces such as antigen-coated glass and planar lipid bilayers containing freely-diffusing antigen are used to mimic these in vivo interactions. IS formation in these contexts is initiated by the formation of a radially-symmetric, Arp2/3 complexdependent branched actin network at the outer edge of the IS (i.e. in the distal supramolecular activation cluster or dSMAC) $(7,8)$. This lamellipodia-like actin network drives the spreading of the $B$ cell across the antigen-coated surface, thereby promoting BCR: antigen interactions $(3,9)$. Once the B cell is fully spread, the continued polymerization of branched actin at the outer edge of the dSMAC generates a centripetal or retrograde flow of actin that drives the movement of BCR: antigen clusters $(10-12)$ towards the center of the synapse (i.e. to the central SMAC or CSMAC) $(8,13)$. This centripetal actin flow, combined with an overall contraction of the $B$ cell, is thought to be responsible for the transport of BCR: antigen clusters to the center of the maturing synapse (13). Importantly, this process of antigen centralization is required for robust $\mathrm{BCR}$ signaling $(3,11,14)$, and is thought to be a prerequisite for antigen internalization by follicular B cells (15-17).

Antigen-induced IS formation scales with the strength of antigen-induced signals such that IS formation and B cell activation are attenuated when membrane-bound antigen binds the BCR weakly or is presented at low density. Importantly, co-stimulatory signals can promote IS formation and $\mathrm{B}$ cell activation under both of these conditions $(18,19)$. Seminal work from Carrasco and colleagues showed that the B-cell integrin LFA-1, which binds the adhesion molecule ICAM-1 present on the surface of APCs (20, 21 ), serves as one such co-stimulatory signal (18). This conclusion was based on four key observations. First, B cells responded robustly to higher affinity membrane-bound antigens presented at high density whether or not ICAM-1 was present on the membrane. Second, the robust activation of $B$ cells in response to antigens of all affinities increasingly required ICAM-1 in the membrane as the density of the antigen was lowered. Third, this co-stimulatory effect was most dramatic for weaker antigens. Finally, this latter effect was not observed in B cells lacking LFA-1. With regard to the underlying mechanism, IRM imaging suggested that LFA-1: ICAM-1 interactions, which were shown to concentrate in the medial portion of the synapse (i.e. the peripheral SMAC or PSMAC), lower the threshold for $B$ cell activation by enhancing cell adhesion. 
While the actin cytoskeleton clearly plays a central role in driving IS formation, whether it plays a specific role in integrin-dependent IS formation is unknown. This is an important question, as most B cell interactions with professional APCs presenting cognate antigen involve integrin ligation. Relevant to this question, the dendritic actin network occupying the outer dSMAC ring, which is thought to be the main driver of IS formation, has been observed primarily in cells that received antigen stimulation alone, and almost exclusively in immortalized B cell lines $(13,22-25)$. It is not known, therefore, whether integrin-co-stimulation alters the organization and/or dynamics of actin at the B-cell IS. Moreover, we are only just beginning to elucidate the organization and dynamics of synaptic actin networks formed by primary B cells. Here we show that LFA-1: ICAM-1 interactions in primary $B$ cells stimulate the formation of a contractile actomyosin arc network that occupies the PSMAC portion of the synapse. This actomyosin network represents the major actin structure at the IS of primary B cells receiving integrin co-stimulation, and its dynamics drive antigen centralization by sweeping antigen centripetally. Importantly, under conditions of limiting antigen, where integrin co-stimulation is required for IS formation, blocking the contractility of this pSMAC network inhibits IS formation and BCR signaling. Finally, we show that germinal center (GC) B cells can also create this actomyosin structure, suggesting that it may contribute to the function of GC B cells as well. Together, our data demonstrate that a contractile actomyosin arc network created downstream of integrin ligation plays a major role in the mechanism by which integrin co-stimulation promotes $B$ cell activation and IS formation when antigen is limiting. Importantly, these findings highlight the need for including integrin co-stimulation when examining the role of actin during $B$ cell activation, especially under physiologically relevant conditions. 


\section{Results}

\section{Integrin co-stimulation promotes the formation of an actin arc network in the PSMAC}

To investigate the possibility that LFA-1 ligation might also promote B cell activation by triggering a significant change in synaptic actin organization, we imaged $\mathrm{F}$ actin at ISs formed by primary mouse B cells on glass surfaces coated with either antiIgM or anti-IgM plus ICAM-1. F-actin was visualized using GFP-F-Tractin, a dynamic reporter for F-actin $(26,27)$, and two super-resolution imaging modalities: Airyscan ( $x y$ resolution $\sim 140 \mathrm{~nm}$ ) and total internal reflection-structured illumination (TIRF-SIM; $x y$ resolution $\sim 100 \mathrm{~nm}$ ). Individual video frames of anti-lgM-engaged $B$ cells using both imaging modalities (Figure 1A, B), together with the corresponding videos (Videos $1 \mathrm{~A}$ and $1 \mathrm{~B}$ ), revealed a thin, bright, highly-dynamic outer rim of F-actin (white arrows in Figure $1 \mathrm{~A}, \mathrm{~B}$ ) that likely corresponds to the branched actin network comprising the dSMAC $(13,22,25)$. Both modalities (but especially TIRF-SIM) showed that the F-actin present inside this outer dSMAC rim is composed of a highly disorganized mixture of short actin filaments/fibers and actin foci (blue brackets in Figure 1A, B), similar to those observed previously in HeLa cells (28). In sharp contrast, individual video frames of anti-IgM+ICAM-1-engaged $B$ cells using both modalities (Figure 1C, D), together with the corresponding videos (Videos $2 \mathrm{~A}$ and $2 \mathrm{~B}$ ), showed a highly organized network inside the outer dSMAC rim (i.e. in the pSMAC) that is comprised of concentric actin arcs (blue brackets and red arrows in Figure 1C, D). The difference in synaptic actin organization between anti-lgM-engaged $B$ cells and anti-lgM+ICAM-1-engaged $B$ cells is very evident in enlarged TIRF-SIM images. While it is challenging to define SMAC boundaries and any pattern of F-actin organization in the pSMAC of $B$ cells engaged with anti-IgM alone (Figure 1E1, E2), SMAC boundaries and pSMAC F-actin organization are both very distinct in $B$ cells engaged using anti-IgM+ICAM-1 (Figure 1F1, F2). Consistently, scoring B cells for the presence of any discernable arcs showed that the addition of ICAM-1 increases the percentage of such cells from $\sim 30 \%$ to $\sim 70 \%$ (Figure 1G). Importantly, static and dynamic imaging showed that the arcs in cells engaged with anti-IgM alone are sparse and transient (Figure 1A, B; Videos 1A and 1B), while those in cells engaged with both anti-IgM and ICAM-1 are dense and persistent (Figure 1C, D; Videos 2A and 2B). In other words, when B cells receiving only anti-lgM stimulation do form discernable arcs (see, for example, those marked by magenta arrows in Figure 1A, B), they are much sparser and less persistent than those formed by cells also receiving ICAM-1 stimulation. Moreover, we could not find any $B$ cells receiving anti-lgM stimulation alone that possessed a robust actin arc network. Consistently, measuring the degree of alignment between actin filaments in the pSMAC portion of $B$ cells stimulated with anti-lgM alone versus both anti-lgM and ICAM-1, which were made using FibrilTool (29), revealed a large shift towards more organized pSMAC 
actin when ICAM-1 was included (Figure 1 - figure supplement 1A1-A3; see the figure legend for details). Finally, measuring the percentage of total synaptic F-actin content within each SMAC (Figure $1 \mathrm{H}$ ), and the percentage of total IS footprint occupied by each SMAC (Figure 1I), showed that the actin arc-containing pSMAC comprises the major actin network at the IS of primary B cells engaged using both anti-IgM and ICAM1. Together, these results demonstrate that LFA-1 co-stimulation promotes the formation of a pSMAC actin arc network that dominates the B cell IS.

\section{Linear actin filaments generated by the formin mDia1 at the outer edge of the synapse give rise to the PSMAC actin arc network}

We next sought to define the origin of the actin arcs that comprise the PSMAC of $B$ cells stimulated using both anti-IgM and ICAM-1. Primary $B$ cells stimulated in this way exhibit small, actin-rich surface spikes at the outer synapse edge (Figure 2A). Importantly, magnified images revealed that the actin within these spikes continues into the cytoplasm in the form of linear actin filaments (Figure 2B1, B2). Moreover, tracing these linear actin filaments showed that they are contiguous with the pSMAC actin arcs (Figure 2C1, C2; Videos 3A and 3B). These results argue that linear actin filaments nucleated at the plasma membrane at the outer edge of the synapse give rise to the actin arcs populating the PSMAC. While these results do not identify the specific nucleator involved, they do point to it being a member of the formin family based on the fact that the actin being made is linear and nucleated at the plasma membrane $(30,31)$. Consistent with this conjecture, and with the fact that formins incorporate fluorescent protein-labelled actin monomer into filaments poorly $(26,27,32)$, we did not see fluorescent actin arcs in B cells expressing mEOS-labeled G-actin (Video 4).

To test if a formin is indeed responsible for creating the pSMAC actin arc network, we used the pan-formin inhibitor SMIFH2 (33). Figure 2D1 and 2D2, together with the line scan in Figure 2E, show that the pSMAC actin arcs present in a representative primary $\mathrm{B}$ cell immediately before SMIFH2 addition (blue trace) had largely disappeared 6 minutes after adding SMIFH2 (red trace). Given recent concerns about the specificity of SMIFH2 (34), we used three different miRNAs to knock down the formin mDia1 in the lymphoma B cell line A20 (Figure 2 - figure supplement 1A, B), which also forms pSMAC actin arcs when stimulated using anti-IgG+ICAM-1 (Figure 1J1, J2; Video 5A). mDia1 was chosen as the miRNA target as it is highly expressed in $B$ cells (Immgen Database) and is largely responsible for making linear actin filaments in T cells (27). Compared to control A20 B cells (Figure 2F1), representative B cells expressing each of the three miRNAs (Figure 2F2-F4) were largely devoid of actin arcs. This difference was supported by quantitating the ratio of pSMAC to dSMAC F-actin (Figure 2G), as well as the amount of F-actin in the pSMAC (Figure $2 \mathrm{H}$ ). Finally, actin arcs were unaffected by the expression of a non-targeting miRNA (Figure 2 - figure 
supplement $1 \mathrm{C1}-\mathrm{C} 4)$. Together, these results argue that the pSMAC actin arcs are indeed created by a formin, and that the formin mDia1 likely plays a major role.

To provide further evidence that the arcs are created by a formin, we imaged A20 $B$ cells following the addition of the Arp2/3 inhibitor CK-666. The rationale for this experiment lies in the recent revelation that the two major consumers of actin monomer in cells, the Arp2/3 complex and formins, are always competing for a limiting pool of actin monomer (35-38). One consequence of this competition is that when one of these nucleators is inhibited, the actin structures created by the other nucleator get more robust because that nucleator now gets more monomer. For example, inhibiting the Arp2/3 complex promotes the formation of formin-dependent actin networks in both yeast and vertebrate cells $(27,35-38)$. Given this, and assuming that the arcs in B cells are formin-generated, then inhibiting the Arp2/3 complex in B cells should lead not only to a diminution of the branched actin network in the dSMAC, but also to an amplification of the arc network in the pSMAC. Consistently, Figure 2 - figure supplement 2A1/A2 (before CK-666 addition) and Figure 2 - figure supplement 2A3/A4 (after CK-666 addition) together show that CK-666 addition leads not only to a reduction in the size of the dSMAC (red brackets), but also to an increase in arc content in the PSMAC (blue brackets). These changes were supported by measuring the percentage of total synaptic F-actin content residing within each SMAC (Figure 2 - figure supplement 2B), which revealed a significant shift away from dSMAC F-actin and toward pSMAC F-actin following CK-666 treatment. This shift was also reflected in measurements of total pSMAC F-actin content (Figure 2 - figure supplement $2 \mathrm{C}$ ), the ratio of pSMAC to cSMAC F-actin content (Figure 2 - figure supplement 2D), and the ratio of pSMAC to cSMAC area (Figure 2 - figure supplement $2 \mathrm{E}$ ). Taken together, these data argue strongly that linear actin filaments generated by the formin mDia1 at the outer edge of the synapse give rise to the pSMAC actin arc network.

\section{Myosin 2A co-localizes with the actin arcs}

Having established that ICAM-1 co-stimulation promotes the formin-dependent formation of actin arcs in the pSMAC, we asked how these arcs are organized into concentric structures. Formin-derived linear actin filaments are commonly organized into well-defined structures such as stress fibers, transverse arcs, and the contractile ring in dividing cells by bipolar filaments of the actin-based motor protein myosin 2 (3941). We decided, therefore, to test whether myosin 2 co-localizes with the actin arcs and is required for their concentric organization.

To define the localization and dynamics of myosin 2 at the B cell IS, we used primary $B$ cells isolated from a mouse in which GFP had been knocked into the $\mathrm{N}$ terminus of the myosin $2 \mathrm{~A}$ (M2A) heavy chain gene (42), as M2A is the only myosin 2 isoform expressed in B cells (Immgen Database). Individual video frames of these cells 
following transfection with Td-Tomato-F-Tractin and attachment to coverslips coated with anti-IgM and ICAM-1 revealed a dramatic co-localization between M2A and the actin arcs in the pSMAC (Figure 3A1-A3; Video 6). Magnified TIRF-SIM images show that the myosin signals align with actin arcs in a periodic fashion (Figure 3A4) that resembles other myosin 2-rich, linear actin structures like stress fibers and the contractile ring (43). Moreover, these myosin signals exhibit the SIM signature for M2A bipolar filaments when M2A is GFP-labeled at its N-terminus (44), which is a pair of GFP puncta spaced $\sim 300 \mathrm{~nm}$ apart (Figure $3 A 5 ; 304 \pm 32 \mathrm{~nm} ; \mathrm{n}=230$ filaments from 12 cells). The presence of M2A filaments in the medial portion of the synapse was also evident in primary $B$ cells isolated from a mouse in which mCherry had been knocked into the $\mathrm{N}$-terminus of M2A (Figure 3 - figure supplement $1 \mathrm{~A}$ ), in primary $\mathrm{B}$ cells that we genome edited using CRISPR to place GFP at the N-terminus of M2A (Figure 3 - figure supplement $1 \mathrm{~B}$ ), and in A20 B cells that we genome edited using CRISPR to place mScarleti at the N-terminus of M2A and then transfected with GFP-F-Tractin (Figure 3 figure supplement 1C1-C3; Video 5B). Finally, 3D-SIM images of A20 B cells that were fixed and stained for M2A and actin showed that endogenous M2A also co-localizes with the actin arcs (Figure 3 - figure supplement 1D1-D3; note that the signature for M2A filaments using this antibody, which recognizes the $C$-terminus of M2A, is a single fluorescent punctum that corresponds to the center of an individual M2A filament (43, 45)). The extent of this colocalization was even clearer in enlarged images of immunostained cells (Figure 3 - figure supplement 1E1-E3), where line scans showed endogenous M2A coinciding with actin arcs (Figure 3 - figure supplement $1 \mathrm{~F}$ ). Together, these results show that the actin arc network in primary $B$ cells receiving ICAM-1 co-stimulation is in fact an actomyosin arc network.

To gain insight into how the arcs become decorated with M2A filaments, we examined time lapse TIRF-SIM images of GFP-M2A knockin primary B cells expressing Td-Tomato F-Tractin. Individual video frames (Figure 3B1-B6), as well as the corresponding video (Video 7), show that bipolar filaments of M2A begin to appear near the dSMAC: pSMAC boundary in association with the linear actin filaments/bundles exiting the dSMAC (white, yellow and fuchsia arrowheads mark such myosin filaments at time $0 \mathrm{~s}$ in Figure 3B1). As time progresses, these filaments move centripetally and undergo expansion into filament clusters (Figure 3B1-B6; see also Video 7). This expansion, in which individual myosin filaments expand into a small cluster of filaments, is presumably driven by the same sequential amplification pathway described previously for M2A filament assembly in fibroblasts (44). Finally, the myosin filaments in these clusters begin to align with the arcs forming at the outer edge of the pSMAC, which then merge with the larger actomyosin arc network in the pSMAC (Figure 3B1-B6). As all this is happening, new myosin filaments keep appearing near the dSMAC: pSMAC boundary to repeat the process (Figure 3B2-B6; follow the blue, green and purple arrowheads). 
Given that ICAM-1 co-stimulation promotes the formation of actin arcs, and that the arcs recruit M2A, ICAM-1 co-stimulation should also result in an increase in the amount of M2A at the IS. Consistently, primary GFP-M2A knockin B cells receiving both anti-lgM and ICAM-1 stimulation exhibited a greater amount of synaptic M2A than B cells receiving only anti-IgM stimulation (Figure 3C-3E). Of note, this difference remained significant even after normalizing the $\mathrm{M} 2 \mathrm{~A}$ fluorescence for a small difference in the average cell-spread area under these two conditions (Figure 3 - figure supplement $1 \mathrm{G} 1-\mathrm{G} 2)$.

\section{Myosin 2A contractility is required for the concentric organization of the actin arcs and for integrin-dependent traction force}

The organization of formin-generated linear actin filaments into well-defined structures is typically driven by the contractility of myosin 2 filaments $(39,40)$.

Therefore, we asked if M2A contractility is required for the concentric organization of the pSMAC actin arcs by treating cells with para-nitroblebbistatin (pnBB), a blue lightinsensitive version of the cell-permeable, small molecule myosin 2 inhibitor blebbistatin (BB) that blocks myosin 2-based contractility by locking the myosin in its weak actin binding state (46). While control, DMSO-treated cells exhibited concentric actin arcs in their pSMAC as expected (Figure 3F), cells treated with $25 \mu \mathrm{M}$ pnBB displayed highlydisorganized, mesh-like actin arrays in their pSMAC (Figure 3G). Consistently, anisotropy measurements made using FibrilTool revealed a dramatic shift towards more disorganized pSMAC actin when B cells are treated with pnBB (Figure $3 \mathrm{H}$ ). Together, these results demonstrate that $\mathrm{M} 2 \mathrm{~A}$ contractility is indeed required for the concentric organization of the pSMAC actin arcs.

We used traction force microscopy in combination with pnBB to ask if integrindependent traction forces that $B$ cells exert on a deformable substate require M2A contractility. As expected $(47,48)$, B cells engaged with substrate coated with anti-lgM and ICAM-1 generated significantly more traction force than $B$ cells engaged with substrate coated with anti-IgM alone (Figure 3 - figure supplement 2A1, A2, B1, B2, D). Importantly, ICAM-1-dependent traction forces were completely abrogated by pretreating the cells with pnBB (Figure 3 - figure supplement $2 \mathrm{C1}, \mathrm{C} 2, \mathrm{D}$ ), indicating that the generation of integrin-dependent traction forces requires $\mathrm{M} 2 \mathrm{~A}$ contractility. This requirement likely reflects pulling forces exerted by M2A on the substrate through LFA1: ICAM-1 pairs, combined with the increase in M2A content at the synapse caused by ligating LFA-1 with ICAM-1, and the contribution that M2A-dependent pulling forces make in keeping LFA-1 in its open, active conformation (49-51). These results, together with the fact that integrin clusters are known to accumulate in the pSMAC portion of the $B$ cell IS $(18,19)$, suggest a feed-forward relationship where integrin ligation promotes the formation of pSMAC actomyosin arcs, and the contractile forces exerted by these actomyosin arcs promote further integrin activation and robust adhesion in the pSMAC. 


\section{The actomyosin arc network in the PSMAC exhibits centripetal flow}

Inward flows of cortical actin networks are thought to drive the transport of antigen receptor clusters to the center of maturing synapses in both $T$ cells and $B$ cells $((7,38,52)$; although see $(53,54))$. For $B$ cells, the clearest example of this to date is the demonstration that the centripetal flow of the branched actin network comprising the dSMAC propels BCR: antigen clusters towards the cSMAC (13). As a prelude to asking whether the actomyosin arcs comprising the PSMAC also contribute to antigen centralization, we asked if this contractile network exhibits centripetal flow. Kymograph analyses of actin flow across synapses made by primary B cells expressing GFP-FTractin showed that their PSMAC actomyosin arc network indeed flows centripetally at $1.07+/-0.07 \mu \mathrm{m} / \mathrm{min}$, or about one third the rate of centripetal actin flow in the dSMAC $(2.89+/-0.18 \mu \mathrm{m} / \mathrm{min})$ (Figure 4 - figure supplement 1A1-A3). Similar results were obtained for A20 B cells (pSMAC rate: $0.97+/-0.13 \mu \mathrm{m} / \mathrm{min}$; dSMAC rate: $3.16+/-0.35$ $\mu \mathrm{m} / \mathrm{min}$ ) (Figure 4 - figure supplement 1B1-B3). Together, these results indicate that the actomyosin arcs could contribute along with the branched actin network in the dSMAC to the inward transport of BCR: antigen clusters.

\section{Actomyosin arcs contribute to antigen centralization by sweeping BCR: antigen clusters inward}

We used planar lipid bilayers (PLBs) to determine if the actomyosin arcs do in fact contribute to antigen centralization. As expected, primary B cells expressing GFPF-Tractin readily formed actin arcs when PLBs contained both anti-IgM and ICAM-1 (Video 8A), but not when they contained anti-IgM alone (Video 8B). Also as expected, primary $B$ cells engaged with PLBs containing fluorescent anti-lgM (red) and unlabeled ICAM-1 yielded mature synapses in which concentric actin arcs surrounded antigen accumulated in the cSMAC (Figure 4A1-A3, white arrows). To obtain a holistic view of antigen centralization, we imaged antigen clusters in the dSMAC and PSMAC of primary $B$ cells over time with the aim of correlating their rates of centripetal transport with the distinct rates of centripetal actin flow exhibited by these two IS zones (Video 9). Tracking of single antigen microclusters showed that they moved inward at $2.36+/-1.1$ $\mu \mathrm{m} / \mathrm{min}$ and $1.03+/-0.3 \mu \mathrm{m} / \mathrm{min}$ across the dSMAC (red tracks) and pSMAC (green tracks), respectively (Figure 4B and $4 \mathrm{C}$ ). Importantly, these rates are very similar to the rates of centripetal actin flow across the dSMAC and PSMAC, respectively (Figure 4 figure supplement $1 \mathrm{~A} 1-\mathrm{A} 3)$. Together, these observations argue that the pSMAC actomyosin arc network works together with the dSMAC branched actin network to drive antigen centralization.

To identify the mechanism by which the actomyosin arcs drive antigen centralization, we imaged F-actin and anti-lgM in the medial portion of forming synapses at high magnification using TIRF-SIM. Anti-IgM microclusters were seen to move across 
the PSMAC towards the cSMAC (which in the following images was in the down direction) while embedded in an arc network moving in the same direction (Video 10). White lines in Video 10 and in the corresponding still images in Figure 4D1-D6 mark actin arcs that were sweeping an individual anti-lgM microcluster inward (Figure 4E1E6). Figure 4F shows the trajectory of this microcluster (temporally color-coded) as it moved towards the cSMAC. Finally, a kymograph of this trajectory (Figure 4G) shows that several actin arcs contributed to the inward movement of this microcluster (areas bracketed in white), and that pauses in movement (areas bracketed in pink) occurred where no actin signal was immediately adjacent to the microcluster. Together, these results argue that individual actin arcs move individual BCR: antigen microclusters inward via a sweeping mechanism that likely depends on frictional coupling between the actin arc and the microcluster (55-57). While arcs can slip past microclusters, the overall incidence of such slippage must be fairly small as the rate of inward antigen transport across the PSMAC (Figure $4 \mathrm{C}$ ) is not significantly slower than the rate of inward actin arc flow across the pSMAC (Figure 4 - figure supplement 1A3).

\section{Integrin ligation-dependent IS formation requires myosin $2 \mathrm{~A}$ contractility}

$B$ cells engaged with membrane-bound antigen at low density fail to centralize antigen unless their integrin LFA-1 is also engaged with ICAM-1 in the target membrane (18). As a prelude to investigating the myosin dependence of this integrin co-stimulatory effect, we sought to recapitulate these findings using primary B cells and PLBs containing varying amounts of mobile, fluorophore-labeled anti-lgM antibody in the presence or absence of unlabeled ICAM-1. Using this approach, we determined an amount of anti-IgM antibody that would not elicit robust antigen centralization in the absence of ICAM-1, but would in its presence. B cells exhibited robust antigen centralization/cSMAC formation over 10 minutes without the need for ICAM-1 when the PLB was loaded using a solution containing anti-lgM at a concentration of $2 \mu \mathrm{g} / \mathrm{ml}$ (hereafter referred to as "high density antigen") (Figure 5 - figure supplement 1A1-A3). By contrast, $B$ cells formed antigen microclusters across their synaptic interface but failed to centralize them over 10 minutes when the PLB was loaded using a solution containing anti-IgM at a concentration $0.15 \mu \mathrm{g} / \mathrm{ml}$ (hereafter referred to as "low or limiting density antigen") (Figure 5 - figure supplement 1B1-B3). Importantly, when unlabeled ICAM-1 was included in these low-density antigen bilayers, B cells now exhibited robust antigen centralization/cSMAC formation (Figure 5 - figure supplement 1C1-C3). This co-stimulatory effect was supported by scoring antigen distribution as centralized, partially centralized or non-centralized (Figure 5 - figure supplement 1D1D3 and E). It was also supported by scoring the percent of total synaptic antigen present within the CSMAC, which was defined by a circular area encompassing $20 \%$ of the entire synaptic interface and centered around the center of mass of the fluorescent antigen-containing pixels within the interface (Figure 5 - figure supplement $1 \mathrm{~F}$ ). Finally, 
it was supported by measuring the size of antigen clusters as a function of their distance from the center of the CSMAC (defined as above) (Figure 5 - figure supplement $1 \mathrm{G}$ ). Specifically, B cells engaged with PLBs containing antigen at the limiting density and no ICAM-1 exhibited small antigen clusters $\left(\sim 0.3 \mu \mathrm{m}^{2}\right)$ located roughly evenly across the synaptic interface (Figure 5 - figure supplement $1 \mathrm{G}$, black trace), while B cells engaged with PLBs containing ICAM-1 in addition to antigen at the limiting density exhibited large antigen clusters (up to $3 \mu \mathrm{m}^{2}$ ), the largest of which were located at the center of the cSMAC (Figure 5 - figure supplement 1G, green trace). Of note, the total amount of antigen present at the synaptic interface was also greater for cells engaged with low density anti-IgM+ICAM-1 than for cells engaged with low density anti-IgM alone (Figure 5 - figure supplement $1 \mathrm{H}$ ). Together, these results recapitulated a central aspect of the integrin co-stimulatory effect described by Carrasco et al. (18), and they established the specific conditions we used next to test the myosin dependence of this co-stimulatory effect.

To score the myosin dependence of the integrin co-stimulatory effect, we measured the ability of primary $B$ cells treated with either vehicle control (DMSO) or pnBB to centralize antigen and form a cSMAC when engaged for 10 minutes with PLBs containing ICAM-1 and anti-IgM at the limiting density. While DMSO-treated cells exhibited robust antigen centralization/cSMAC formation (Figure 5A1-A3), pnBB-treated cells failed to centralize antigen/create a cSMAC (Figure 5B1-B3). Consistently, the actin arcs that surround centralized antigen in DMSO-treated cells (Figure 5C1-C3; white arrows) were absent in pnBB-treated cells (Figure 5D1-D3). The fact that myosin inhibition abrogates the integrin co-stimulatory effect was further supported by scoring antigen distribution in control and pnBB-treated cells as centralized, partially centralized or non-centralized (Figure 5E), by scoring the percent of total synaptic antigen present within the CSMAC (Figure 5F), and by measuring the size of antigen clusters as a function of their distance from the center of the cSMAC (Figure 5G). Of note, the total amount of antigen present at the synaptic interface was also greater for cells treated with DMSO than for cells treated with pnBB (Figure $5 \mathrm{H}$ ). Together, these results show that the ability of integrin ligation to promote antigen centralization and cSMAC formation when antigen is limiting requires myosin contractility. This in turn argues that the contractile actomyosin arc network created downstream of integrin ligation plays an important role in the mechanism by which LFA-1 co-stimulation promotes $B$ cell activation.

Finally, we were curious if the robust centralization of antigen that occurs in the absence of LFA-1 ligation when the density of antigen is high is also dependent on myosin contractility, at least to some extent. Indeed, we found that treatment with paraamino BB (paBB), a newer, slightly more water soluble version of BB (58), attenuated antigen centralization significantly even when the density of antigen was high (Figure 5 
- figure supplement 2; see legend for details), although the magnitude of the inhibition was smaller than for B cells engaged with limiting antigen plus ICAM-1 (compare the results in Figure 5 - figure supplement 2 to the results in Figure 5). We conclude, therefore, that M2A contractility potentiates antigen centralization when antigen density is high as well as when antigen density is low enough that LFA-1 co-stimulation becomes important for IS formation. That said, additional experiments should help define how myosin contributes to antigen centralization in B cells receiving only strong anti-lgM stimulation.

\section{Myosin 2A contractility promotes BCR-dependent signaling}

To measure the contribution that actomyosin arcs might make to BCR-dependent signaling, we determined the effect that pnBB has on the distribution and synaptic content of phosphorylated CD79a (P-CD79a), an early signaling molecule responsible for signal transduction downstream of BCR-antigen interaction (14, 59). Consistent with results above and with the known properties of CD79a, DMSO-treated primary B cells engaged for 10 minutes with PLBs containing ICAM-1 and limiting antigen and then fixed/stained for P-CD79a exhibited robust cSMAC formation, with P-CD79a and antiIgM concentrated in the cSMAC (Figure 6A1-A4). Also as expected, pnBB-treated B cells failed to form a clear CSMAC, resulting in CD79a and anti-lgM spread across the synapse (Figure 6B1-B4). Importantly, quantitation showed that pnBB-treated cells also exhibited a significant reduction relative to control cells in synaptic P-CD79a content (Figure 6C). This defect was also seen after only 5 minutes on PLBs (Figure 6 - figure supplement $1 \mathrm{~A}$ ), and the defects at both time points were not due to differences between BB-treated cells and control cells in synaptic CD79a content (Figure 6 - figure supplement 1B).

To extend these results, we determined the effect that pnBB has on the distribution and synaptic content of phosphorylated CD19, an important co-receptor for the BCR that is responsible for PI3K activation (3, 60-62). DMSO-treated primary B cells engaged with PLBs as above exhibited robust CSMAC formation, with P-CD19 enriched at the outer edge of the IgM concentrated in the cSMAC (Figure 6D1-D4). This enrichment of P-CD19 at the pSMAC/cSMAC boundary was confirmed by line scans of the fluorescence intensities for F-actin, anti-IgM and P-CD19 (Figure 6G, see boxed pSMAC regions). In contrast to control cells, pnBB-treated B cells failed to concentrate anti-lgM at the center of the synapse, and P-CD19 staining was now spread across the synaptic interface (Figure 6E1-E4 and H). Moreover, quantitation showed that pnBBtreated cells also exhibited a significant reduction relative to control cells in synaptic $\mathrm{P}$ CD19 content (Figure 6F) that was not due to a difference in synaptic CD19 content (Figure 6 -figure supplement 1C). Together, these results indicate that the actomyosin arcs promote BCR-dependent signaling. 


\section{Germinal center B cells can make actomyosin arcs and centralize antigen}

Recent studies have presented evidence that germinal center (GC) B cells differ markedly from naive $B$ cells with regard to the distribution and fate of antigen at mature synapses. Rather than concentrating antigen at the center of the synapse and using actomyosin force to extract it there, GC B cells accumulate antigen in clusters at the periphery of the synapse and use actomyosin force to extract it there $(38,63,64)$. These and other results argue that GC B cells differ dramatically from naïve B cells with regard to the organization of actomyosin at their synapse. We wondered, however, if actomyosin arcs could be detected in mouse GC B cells using our imaging approaches. Consistently, TIRF-SIM imaging of mouse GC B cells isolated from the GFP-M2A knockin mouse that were stained with Cell Mask Deep Red and plated on coverslips coated with anti-IgM, anti-lgG and ICAM-1 revealed a subset of cells exhibiting enrichment of M2A filaments in the medial, pSMAC portion of the synapse (Video 11), just as in naïve $B$ cells. Moreover, these myosin filaments move centripetally (Video 11) and co-localize with pSMAC actin arcs in phalloidin-stained samples (Figure 7A1-A3, white arrows), just as in naive $B$ cells. Importantly, scoring showed that about one third of GC B cells exhibited robust accumulation of M2A filaments in the pSMAC when engaged with anti-lgM/lgG-coated glass (Figure 7B). Similarly, about one third of GC B cells engaged for 10 minutes with PLBs containing fluorophore-labeled anti-lgM/lgG and unlabeled ICAM-1, and then fixed and stained with phalloidin, exhibited robust accumulation of M2A filaments in the pSMAC (Figure 7C1-C4, and D). Importantly, these actomyosin arcs can be seen to surround antigen accumulated at the center of the synapse (see the white arrows in Figure 7C1, C2 and C4). This finding, together with the fact that the myosin moves centripetally during IS formation (Video 11), suggests that actomyosin arcs can contribute to antigen centralization in GC B cells as well as in naïve $B$ cells.

Given these results, we asked if our PLB-engaged mouse GC B cells can centralize antigen. In partial agreement with previous findings $(63,64), \sim 45 \%$ of synapses exhibited small to medium sized antigen clusters distributed to varying degrees in the synapse periphery (Figure 7E1, E2 and F). In addition, 20\% of synapses exhibited antigen microclusters spread throughout the synaptic interface (Figure 7E3 and F). Importantly, the remaining $~ 35 \%$ of synapses exhibited highly centralized antigen (Figure 7E4 and F). Images of these synapses showed a pSMAClike accumulation of GFP-M2A surrounding much of the centralized antigen (Figure 7 figure supplement $1 \mathrm{~A} 1$; see also Video 12). Conversely, images of synapses containing either peripheral antigen clusters or microclusters showed no obvious pattern to the distribution of GFP-M2A (Figure 7 - figure supplement 1A2, A3; see also Video 13). Moreover, these synapses exhibited less total GFP-M2A than the synapses with centralized antigen, and the signals that were present appeared quite transient. These 
results, together with the images in Figure $7 \mathrm{C} 1-\mathrm{C} 4$, argue that $\mathrm{GC} B$ cells with centralized antigen (about one third of cells) are the ones that make actomyosin arcs (again, about one third of cells). We conclude, therefore, that GC B cells can make actomyosin arcs and that they likely use this structure to centralize antigen, although the degree to which they do this is considerably less than for naïve $B$ cells. We note, however, that our conclusions regarding GC B cells require additional supporting data that include testing the ICAM-1 dependence of actomyosin arc formation and quantitating the contributions that this contractile structure makes to GC B cell traction forces, signaling, and antigen centralization. 


\section{Discussion}

Integrin co-stimulation promotes $B$ cell activation and IS formation when antigen is limiting by promoting $B$ cell adhesion $(18,19)$. Here we identified an actomyosindependent component of this integrin co-stimulatory effect. By combining superresolution imaging with specific cytoskeletal perturbations, we showed that integrin ligation induces the formation of a PSMAC actomyosin arc network that comprises the major actin network at the primary $B$ cell IS. This network is created by the formin mDia1, organized into a concentric, contractile structure by the molecular motor M2A, and promotes synapse formation by mechanically sweeping antigen clusters centripetally into the cSMAC. Most importantly, we showed that integrin-dependent synapse formation under conditions of limiting antigen requires M2A, as inhibiting its contractility significantly impairs antigen centralization. Consistently, myosin inhibition also diminishes the synaptic content of the key BCR signaling proteins P-CD79a and PCD19 and disrupts their synaptic distribution. Finally, we showed that a significant fraction of GC B cells also make this contractile pSMAC actomyosin arc network. Together, our results argue that integrin co-stimulation promotes $B$ cell activation and synapse formation not only by enhancing B cell adhesion (18), but also by eliciting the formation of a contractile actomyosin arc network that drives mechanical forcedependent IS formation. These findings invite a critical "reset" for the way in which future B cell studies should be approached by highlighting the need for integrin costimulation when examining the roles of actin and myosin during $B$ cell activation. This reset is especially important given that most in vitro studies of B cell IS formation and activation have been performed under conditions of excess antigen, while antigen is rarely available in excess in vivo.

A central player in the link between integrin co-stimulation and the formation of the actomyosin arc network is almost certainly active RhoA. First, active RhoA would drive arc formation by simultaneously targeting, unfolding and activating mDia1 at the plasma membrane $(65,66)$. Second, active RhoA would drive arc organization and contractility by activating the ROCK-dependent phosphorylation of the regulatory light chains on M2A (45), thereby promoting the assembly of the M2A bipolar filaments that decorate, organize and contract the arcs. Finally, it is likely that active RhoA would promote actomyosin arc formation by activating the ROCK-dependent phosphorylation of mDia1's autoinhibitory domain, thereby blocking its refolding and subsequent inactivation (67-69). Given all this, it seems very likely that integrin ligation promotes actomyosin arc formation at least in part by promoting the loading of RhoA with GTP. Consistent with this idea, adhesion signaling has been linked in a variety of systems to the activation of guanine nucleotide exchange factors (GEFs) for RhoA (e.g. p190RhoGEF, GEF H1) $(70,71)$. Future work should seek, therefore, to clarify the outside-in signaling pathway in $B$ cells that links integrin ligation to the activation of one 
or more GEFs for RhoA. Such efforts should also take into account parallel activation pathways, such as the PI3K-dependent activation of RhoA downstream of BCR signaling (72), the myosin-dependent activation of $B$ cell adhesion downstream of CXCR5 signaling (73), and the diacylglycerol kinase-dependent regulation of adhesion and actomyosin force generation at the B cell synapse (74). Given our results here, the ability of the B-cell integrin VLA-4, which binds VCAM-1 on APCs, to promote IS formation under limiting antigen conditions (19) may also involve an actomyosindependent mechanism. Indeed, actomyosin-dependent B cell IS formation may be a mechanism harnessed by multiple co-stimulatory pathways to promote B cell activation. Finally, future studies should also seek to clarify the extent to which integrin ligation promotes the formation of actomyosin arcs by driving their creation versus stabilizing them once created.

Consistent with our findings, a recent study by Bolger-Munro et al. reported that GFP-tagged M2A localizes to the medial portion of synapses formed by A20 B cells (13). In their hands, however, BB treatment did not inhibit antigen centralization, arguing that synapse formation does not require M2A. The disparity between their results and ours as regards the functional significance of M2A may be due to numerous differences in experimental design, including the cell type used (primary B cells versus the A20 B cell line), the mode of antigen presentation (anti-IgM-containing PLBs versus transmembrane antigen expressed by APCs), and the density of antigen (known in PLBs versus unknown and variable on APCs). Our pSMAC actomyosin arcs may also be related to the myosin-rich regions that form in primary HEL-specific naïve $B$ cells bound to acrylamide gels coated with HEL antigen (48).

The contractile actomyosin structure identified here occupies the portion of the Bcell synapse defined by the presence of an integrin ring, i.e. the pSMAC $(3,18,19,75)$. This co-localization should support a feed-forward relationship where integrin costimulation promotes the formation of the actomyosin arcs, and the contractile forces that these arcs then promote further integrin activation and robust adhesion. Indeed, the $B$ cell $P S M A C$ can be viewed as roughly analogous to the lamellar region of mesenchymal cells, where integrins present within ECM-anchored focal adhesions are kept in their open, extended, high-affinity conformation by the forces that myosin-rich stress fibers exert on them $(76,77)$. By analogy, the contribution that the centering forces exerted by the actomyosin arcs make to integrin activation in the PSMAC may be enhanced in the context of an APC by the fact that the APC restricts ICAM-1 mobility (78). Of note, the activation of integrins by contractile actin arcs created by formins and myosin 2 is also seen in other cell types (79-81).

Recent studies have presented evidence that germinal center (GC) B cells differ dramatically from naïve $B$ cells with regard to the organization of actomyosin at their synapse $(63,64)$. We found, however, that about one third of GC B cells exhibit robust 
actomyosin arcs in the medial, pSMAC portion of their synapse that are indistinguishable from those made by naïve $B$ cells. Moreover, staining data together with images of GFP-M2A distribution in synapses made by PLB-engaged GC B cells suggest that, like naïve B cells, GC B cells can use this contractile structure to centralize antigen. Given that the selection of GC B cells with higher affinity BCRs likely depends to a significant extent on their ability to gather antigen in the context of strong competition for limiting antigen presented by follicular dendritic cells $(2,82)$, we suggest that actomyosin arcs might contribute to this selection process by promoting antigen gathering.

The actomyosin arcs described here in B cells and the actomyosin arcs described previously in T cells (27) have a great deal in common as regards their formation, organization and dynamics $(7,38)$. Consistently, this contractile structure supports a number of synaptic processes that are shared by these two cell types, including antigen centralization, proximal signaling, and the formation of an adhesive ring in the medial portion of the IS. A major question, then, is how these two immune cell types harness the force generated by this shared contractile structure to perform their unique functions, i.e. target cell killing by the T cell and antibody creation by the B cell. Stated another way, how does the $\mathrm{T}$ cell use the force generated by this contractile structure to support the effectiveness of an exocytic event (lytic granule secretion), while the B cell uses the force to support the effectiveness of an endocytic event (antigen extraction and uptake). With regard to T cells, a seminal study by Basu and colleagues (83) showed that actomyosin-dependent forces placed on the target cell membrane by the $\mathrm{T}$ cell increase the efficiency of target cell killing by straining the target cell membrane in such a way as to increase the pore-forming activity of perforin. One clear goal, therefore, is to determine if the T cell's actomyosin arcs are responsible for creating this strain. Imaging the actomyosin arcs during the process of target cell killing, and blocking the force they generate just prior to lytic granule secretion, should reveal their contribution to this essential effector function.

The idea that B cells would use the actomyosin arcs identified here to support the extraction and endocytic uptake of membrane-bound antigens stems from the seminal work of Tolar and colleagues, who showed that M2A plays an important role in antigen extraction $(63,84,85)$. These authors also presented evidence that M2A-dependent pulling forces select for BCRs with higher affinity for antigen, as such interactions survive the myosin-dependent strain placed on them, resulting in antigen extraction $((63,84)$; for review see (7) and (86)). That said, a recent, imaging-based effort to define the mechanism by which antigen is extracted did not provide clear insight into how M2A contributes to this process. Specifically, Roper et al. (87) reported that the synapses of naïve B cells bound to antigen-bearing plasma membrane sheets (PMSs) are composed of a dynamic mixture of actin foci generated by the Arp2/3 complex and disorganized linear filaments/fibers generated by a formin. While static images showed little co-localization between the actin foci and antigen clusters, dynamic imaging suggested that the foci promote antigen extraction (although formin activity was also 
required). Based on these and other observations, Roper et al. concluded that naive $B$ cells use a foci-filament network to drive force-dependent antigen extraction (87). How M2A contributes to this force was unclear, however, as M2A (visualized using an antibody to the phosphorylated form of M2A's RLC) did not co-localize with either actin structure (87). Moreover, neither actin structure was affected by BB treatment. These two findings are notably at odds with our findings that M2A (visualized by endogenous tagging of the M2A heavy chain) co-localizes dramatically with actin arcs, and that BB treatment profoundly disrupts the organization of the PSMAC actin arc network. Regarding this discrepancy, we note that the images of synaptic actin presented by Roper et al. look similar to our images of naïve B cells stimulated with anti-lgM alone, where the synapse was also composed of a disorganized and dynamic mixture of actin foci and short actin filaments/fibers. The fact that the PMSs used by Roper et al. did not contain integrin ligands may explain, therefore, why they did not see a more organized synapse containing actomyosin arcs. In the same vein, two other recent studies examined antigen extraction using substrates that lacked integrin ligands (PLBs and PMSs in (64), and acrylamide gels in (48)). Given our results, we suggest that future efforts to define the mechanism by which M2A promotes antigen extraction should follow the myosin as the $B$ cell extracts antigen from an APC, where the B cell's integrins will be engaged, and where the antigen can be presented in a physiologically relevant way (e.g. opsonized and bound to an Fc or complement receptor). Such efforts will hopefully reveal how the $B$ cell harnesses the forces generated by the actomyosin arcs identified here to drive antigen extraction and uptake. 


\section{Materials and Methods}

\section{Mice and cell culture}

Primary B cells were isolated from the spleens of 6 to 12 week-old C57BL/6 mice (Jackson Laboratories \#002595) and M2A-GFP KI mice (gift of R. Adelstein, $\mathrm{NHLBI} / \mathrm{NIH}$ ) of either sex using negative selection $\mathrm{B}$ cell isolation (StemCell Technologies). Euthanasia was performed in accordance with protocols approved by the National Human Genome Research Institute Animal Use and Care Committee at the National Institutes of Health. The A20 murine $\lg \mathrm{G}^{+} \mathrm{B}$ cell line was purchased from ATCC (ATCC $®$ TIB-208 ${ }^{\mathrm{TM}}$ ), verified by responsiveness to anti-lgG stimulation, and confirmed to be free of mycoplasma. B cells were cultured in complete medium (RPMI1640, 10\% heat-inactivated fetal calf serum (FCS), $2 \mathrm{mM} \mathrm{L-glutamine,} 1 \mathrm{mM}$ sodium pyruvate, $50 \mu \mathrm{M}$ 2-mercaptoethanol and $1 \mathrm{X}$ Antibiotic-Antimycotic) at $37^{\circ} \mathrm{C}$ with $5 \%$ $\mathrm{CO}_{2}$. Primary B cell complete media also contains $5 \mathrm{ng} / \mathrm{ml}$ of BAFF (R\&D Systems).

\section{Plasmids and Reagents}

GFP- and tdTomato-tagged F-Tractin were gifts from Michael Schell (Uniformed Services University, Maryland). Alexa Fluor-conjugated phalloidins were purchased from Thermo Fisher. Anti-mDia1 antibody was purchased from Thermo Fisher (PA527607). HRP-conjugated mouse anti- $\beta$-actin antibody was purchased from Santa Cruz (SC-47778 HRP). Rabbit anti-CD79a (\#3351), anti-PCD79a (\#5173), anti-CD19 (\#3574) and anti-PCD19 (\#3571) were purchased from Cell Signaling Technologies. Anti-M2A was purchased from Millipore Sigma (\#M8064) CK-666 and SMIFH2 were purchased from Millipore Sigma and used at final concentrations of $100 \mu \mathrm{M}$ and $25 \mu \mathrm{M}$, respectively. pnBB and paBB were purchased from Cayman Chemicals and used at a final concentration of $25 \mu \mathrm{M}$. DMSO vehicle control was purchased from Millipore Sigma. CellMask ${ }^{\mathrm{TM}}$ Deep Red Plasma Membrane Stain was purchased from Thermo Fisher. Alexa Fluor 488- (\#111-545-003), 594- (\#111-585-003) and 647- (\#111-605-003) conjugated goat, anti-rabbit secondary antibodies were purchased from Jackson ImmunoResearch. Goat anti-mouse IgG Fcy fragment specific antibody (\#115-005-008) and goat anti-mouse IgM, $\mu$-chain specific antibodies (\#115-005-020) were purchased from Jackson ImmunoResearch. Anti-rabbit-HRP (\#32260) was purchased from Thermo Fisher.

\section{GC B cell generation and sorting}

GC B cells were generated and sorted using a previously described protocol (88). Briefly, 6 to 12 week-old M2A-GFP KI mice were immunized with sheep's red blood cells. After 8 to 10 days, total $B$ cells from the spleens and lymph nodes were isolated using the Negative Selection B cell isolation kit (Stemcell Technologies) according to the manufacturer's instructions. Dead cells were stained using Zombie Yellow viability 
stain (Biolegend) and Fc receptors were blocked with the mouse TruStain FcX ${ }^{\mathrm{TM}}$ antibody (\#156604). Cells were immunostained with anti-mouse CD38 (\#102719), B220 (\#103235) and GL-7 (\#144617) purchased from Biolegend. GC B cells were sorted on a BD Aria III FACs sorter (Beckton Dickinson) for GFP+, Zombie Yellow-, B220+, CD38 low and $\mathrm{GL}-7^{+}$cells, and were used immediately.

\section{B cell transfection}

A20 B cells and primary B cells were transfected as previously described (25). Briefly, ex vivo primary $B$ cells were first cultured for $12 \mathrm{~h}$ in complete media supplemented with $5 \mathrm{ng} / \mathrm{ml}$ BAFF (R\&D Systems) and $2.5 \mu \mathrm{g} / \mathrm{ml}$ Escherichia coli 0111:B4 LPS (Millipore Sigma) (LPS was included to promote cell survival during nucleofection). $2 \times 10^{6} \mathrm{~B}$ cells were then nucleofected with $2 \mu \mathrm{g}$ of plasmid DNA using Nucleofector Kit V (Lonza) and rested for at least 16-24 hours using complete media containing $5 \mathrm{ng} / \mathrm{ml}$ BAFF and lacking LPS. We refer to both rested, transfected cells and ex vivo non-manipulated cells as naïve $B$ cells because neither had been activated by antigen.

\section{CRISPR}

Mouse GFP-M2A and Scarleti-M2A template plasmids were gifts from Jordan Beach (Loyola University, Chicago). Mouse M2A sgRNAs were synthesized by Synthego and used according to the manufacturer's instructions. Briefly, sgRNAs were mixed with Cas9 (IDT) to form ribonucleoproteins and then added together with $0.5 \mu \mathrm{g}$ of template plasmid to $2 \times 10^{6}$ cells suspended in the solution for Nucleofector kit V. Following nucleofection, the cells were cultured in complete media for 24 hours before Fluorescence-activated cell sorting (FACS) for GFP or Scarleti expression using the Aria III (Becton Dickinson).

\section{miRNA-mediated knockdown of mDia1}

miRNAs targeting the 3' UTR of mouse mDia1 were designed as previously described (89) using BLOCK-iT RNAi Designer (Thermo Fisher), synthesized (Gene Universal), and fused to the C-terminus of mNeonGreen-F-Tractin using In-Fusion cloning (Takara). As a control, a version of this plasmid containing a miRNA sequence that has been verified as non-targeting in mouse (90) was used. A20 B cells were transfected with 2 $\mu \mathrm{g}$ of F-Tractin-mNeonGreen vector control, F-Tractin-mNeonGreen-mDia1-miRNAs, or the F-Tractin-mNeonGreen-nontargeting miRNA and cultured in complete media for 16 hrs. Cells were then lysed and immunoblotted using an antibody to mDia1 (1:250) and an HRP-conjugated antibody to $\beta$-actin (1:5000) to confirm knockdown. Cells that had received the miRNA were identified based on the expression of F-Tractin-mNeonGreen and then quantified using phalloidin staining. F-Tractin-mNeonGreen-positive cells were also used in a cell spreading assay as described below. 


\section{Cell spreading on functionalized glass}

8-well Labtek chambers (Nunc) were coated with $15 \mu \mathrm{g} / \mathrm{ml}$ of anti-lgM and/or anti-lgG with or without $0.5 \mu \mathrm{g} / \mathrm{ml}$ of mouse histidine-tagged ICAM-1 (Sino Biological) for 1 hour at room temperature. B cells were resuspended in modified HEPES-buffered saline (mHBS) (25) and adhered to functionalized glass for $15 \mathrm{~min}$ at $37^{\circ} \mathrm{C}$ before live-imaging or fixing with $4 \%$ paraformaldehyde for staining (see SI Materials and Methods). Where inhibitors were used, cells were pretreated for $30 \mathrm{~min}$ with $100 \mu \mathrm{M}$ CK-666, $25 \mu \mathrm{M}$ $\mathrm{SMIFH} 2,25 \mu \mathrm{M}$ pnBB or paBB, or $\mathrm{dH}_{2} \mathrm{O} / \mathrm{DMSO}$ vehicle control in mHBS at $37^{\circ} \mathrm{C}$. Cells were then added to functionalized Labtek chambers in mHBS containing the same concentrations of inhibitors or vehicle control as the pretreatment.

\section{Supported planar lipid bilayers}

Liposomes were prepared as described previously $(26,27,91)$. Briefly, $0.4 \mathrm{mM} \mathrm{1,2-}$ dioleoyl-sn-glycero-3-phosphocholine, biotin-CAP-PE, 1,2-dioleoyl-sn-glycero-3-[( $N$-(5amino-1-carboxypentyl)iminodiacetic acid)succinyl] (DGS)-NTA and 1,2-dioleoyl-snglycero-3-phosphocholine (Avanti Polar Lipids, Inc.) were mixed at 1:3:96 molar \% ratio. Lipids were dried under a stream of argon and then desiccated in a vacuum chamber. Unilamellar liposomes were generated from lyophilized lipids hydrated in Tris-buffered saline via extrusion through a $50-\mathrm{nm}$ pore membrane using a mini-extruder kit (Avanti Polar Lipids, Inc.). PLBs were assembled in Sticky-Slide $\mathrm{VI}^{0.4}$ Luer closed chambers (Ibidi) as previously described (92). $25 \times 75$-mm glass coverslips (Ibidi) were cleaned using Piranha solution (1:3 ratio of sulfuric acid and $30 \%$ hydrogen peroxide). After depositing liposomes onto the flow channels, the channels were washed with HBS buffer containing 1\% BSA. A solution containing mono-biotinylated, Alexa Fluor 647labeled anti-lgM antibody $\left(0.15 \mu \mathrm{g} / \mathrm{ml}\left(300\right.\right.$ molecules $\left./ \mu \mathrm{m}^{2}\right)$ for the limiting antigen condition and $2 \mu \mathrm{g} / \mathrm{ml}$ (4000 molecules $\left./ \mu \mathrm{m}^{2}\right)$ for the high antigen condition) and streptavidin (Sigma-Aldrich) were added to the flow chambers with or without $0.5 \mu \mathrm{g} / \mathrm{ml}$ unlabeled histidine-tagged ICAM-1. Anti-IgM antibody ( $\mu$-chain specific) was monobiotinylated and labeled with Alexa Fluor 647 (Thermo Fisher) as described previously (18). The uniformity and lateral mobility of PLBs were assessed using FRAP as described previously (26). Photobleached circles with a diameter of $4 \mu \mathrm{m}$ typically recovered within 60 seconds. B cells were resuspended in modified HEPES-buffered saline and allowed to engage PLBs at $37^{\circ} \mathrm{C}$ and imaged immediately, or fixed with $4 \%$ paraformaldehyde after 5 and 10 mins for immunostaining.

\section{Traction force microscopy}

Polyacrylamide gels (PA, $0.23 \mathrm{kPa}$ shear modulus, $40 \mu \mathrm{m}$ thickness) were prepared on glass coverslips with embedded $40 \mathrm{~nm}$ fluorescent beads (TransFluoSpheres (633/720), Thermo Scientific), as described previously (93). B cells were resuspended in $\mathrm{mHBS}$ with $2 \%$ FCS and added to PA gels. Images of B cells that had engaged PA gels for 20 
mins were captured. A no-stress reference image of the PA gels with beads was captured after lifting cells from the PA gel by adding $1 \%$ sodium dodecyl sulfate in $1 \mathrm{X}$ PBS to the imaging chamber at a final concentration of $0.04 \%$. Particle image velocimetry was used to calculate bead displacements relative to the reference position, and the corresponding contractile energy was quantified using ImageJ plugins as previously described $(93,94)$. Traction forces were reported as the mean magnitude of traction stress within the cell relative to the cell surface area.

\section{Immunostaining}

Fixed cells were permeabilized with $0.2 \%$ Triton-X-100 and blocked for 30 min at room temperature using PBS containing $2 \%$ BSA. Cells were incubated with primary antibodies (1:200) overnight at $4^{\circ} \mathrm{C}$ and then secondary antibodies (1:250) with Alexa Fluor-conjugated phalloidins for $1 \mathrm{~h}$ at room temperature. Antibodies and phalloidins were diluted in blocking buffer. All washes were performed with $1 \mathrm{X}$ PBS.

\section{Microscopy}

All live cell imaging was performed at $37^{\circ} \mathrm{C}$ in mHBS supplemented with $2 \% \mathrm{FCS}$. TIRF-SIM and 3D-SIM imaging were performed on a GE DeltaVision OMX SR microscope (Cytiva) equipped with a 60X 1.42 NA oil objective (Olympus). For 3D-SIM, $z$-stacks were acquired at $0.125 \mu \mathrm{m}$ increments. Raw data were reconstructed using Softworx software (Cytiva) with a Wiener filter constant of 0.002-0.003. Airyscan imaging was performed using an LSM 880 Zeiss confocal microscope equipped with Airyscan and using a Plan-Apochromat 63X 1.4 NA oil objective. Airyscan image reconstruction was performed using Zeiss ZEN imaging software. TFM was imaged using a Nikon Eclipse Ti2 microscope equipped with a 60X 1.2 NA water objective. Linear adjustments to images were made using ImageJ 1.53 (NIH).

\section{Image analyses}

All image analyses were performed using ImageJ $(\mathrm{NIH})$. To draw ROls for measurements of the fraction of total IS footprint occupied by each SMAC, the content of F-actin in each SMAC, and the anisotropy of actin filaments within the pSMAC, we relied on the distinctive appearance of actin in each SMAC. This was straightforward in TIRF-SIM images of B cells stimulated with both anti-IgM and ICAM-1, where the thin outer dSMAC was comprised of moderately bright pixels with not much fluctuation in intensity, the medial PSMAC was comprised of bright actin arcs with intervening dim signals, and the central cSMAC was comprised mostly of dim signals. For B cells engaged with anti-IgM alone, the thin outer dSMAC was still readily identifiable, the central CSMAC was identifiable in lower mag images as a central circle with less signal than the area between it and the dSMAC, and the medial pSMAC corresponded to the area between the ISMAC and the CSMAC. Fluorescence intensities within the SMAC 
regions were quantified using $\mathrm{RO}$ s and reported as the total background-corrected fluorescence within the ROI, which was quantified as described (95) using the following equation: Integrated density-[(area of $\mathrm{ROI}) \times$ (mean background fluorescence per unit area)], where the integrated density is equal to [(area of ROI) $\times$ (mean fluorescence per unit area within the $\mathrm{ROI}$ )]. Mean background fluorescence was determined using the same ROI size at 3 separate positions less than $3 \mu \mathrm{m}$ away from the cell. The myosin fluorescence intensity in 3D SIM images was quantified using a maximum projection image of the image stacks where the cell ROI was determined based on the F-actin threshold and the background-corrected myosin fluorescence within the cell ROI was reported. The FibrilTool plugin for ImageJ was used to measure actin arc morphology based on the intensity gradients between pixels as described previously $(27,29)$. Briefly, the PSMAC regions in TIRF-SIM images were divided into 10-12 trapezoidshaped ROls of similar size to measure the anisotropy of arcs in the radially symmetric pSMAC. The values obtained range from 0 , when the orientation of the structures is random, to 1, when the structures show higher orientation in the same direction. The velocity of centripetal actin flow was assessed by assembling kymographs from TIRFSIM videos using the Kymograph Builder plugin from ImageJ, as previously described (27). Briefly, the dSMAC and pSMAC regions were identified by the relatively abrupt slope change for F-actin flow, and slope angles were used to quantify the rates of actin movement. The size of each antigen cluster and their relative distance from the cSMAC center were quantified using an ImageJ macro. First, the perimeter of the synaptic interface was determined based on thresholds for F-actin, and an ROI that encompassed the interface area was drawn (the synaptic ROI). The coordinates for each pixel contained in the ROI was determined and the linear distance of each pixel from the center of mass of the total synaptic antigen (defined as CSMAC center) was determined. The longest distance was defined as the furthest distance to travel from the outermost edge of the cell. A binary image of the antigen channel combined with the ImageJ watershed algorithm was used to segment individual antigen clusters within the synaptic ROI. The area of each antigen cluster was quantified using the Analyze Particles function in ImageJ. The relative distance of each antigen cluster was reported as the distance between the center of mass of the antigen cluster and the cSMAC center after normalizing to the furthest distance from the cell edge to the cSMAC center. To quantify the antigen fluorescence in the cSMAC, a circular ROI corresponding to $20 \%$ of the total synaptic area (based on the average area of the cSMAC at the synaptic interface) was drawn such that the center of the circle lies at the same coordinates as the center of mass of the total antigen signal. Antigen fluorescence within this circle was quantified and presented as a percent of the total synaptic antigen fluorescence. The fluorescence intensity of the signaling molecules CD79a, P-CD79a, CD19 and P-CD19 were all reported as the total fluorescence intensity within the synaptic ROI. All fluorescence intensities were corrected for background as described above. 
Fluorescence intensity profiles were obtained by drawing a $10 \mu \mathrm{m}$ line across the center of the synaptic interface and using the ImageJ function "Plot Profiles" to obtain fluorescence intensity values across the line. The intensity profiles of several cells were combined and the average fluorescence intensity \pm standard deviation was reported. The speeds of antigen cluster movement were quantified using the ImageJ plugin TrackMate as previously described (96) where a combination of automated and manual tracking were performed. Prior to quantification, the perimeter of the cell was identified by over-saturating the signal for GFP-M2A, and the anti-lgM fluorescence signal outside of the cell was removed so that only antigen clusters formed by that cell were quantified. Antigen clusters were determined using a blob diameter of $0.2 \mu \mathrm{m}^{2}$ and tracks were obtained using a threshold of 2000 units with sub-pixel localization. Mean antigen cluster movement speeds were reported as distance traveled over time. Kymographs of moving antigen clusters were created using the ImageJ plugin Kymograph Builder.

\section{Statistical analyses}

All statistical analyses were performed using Prism 9 (GraphPad). Statistical comparisons of dot plots were performed using unpaired, two-tailed $t$-tests, and data are represented as mean \pm standard deviation. Statistical comparisons of bar charts were performed using paired, two-tailed $t$-tests, and data are represented as mean \pm standard error of the mean. The following annotations are used to indicate significance: ${ }^{*}=\mathrm{P}<0.05,{ }^{* *}=\mathrm{P}<0.01,{ }^{* * *}=\mathrm{P}<0.001$, and ${ }^{* * * *}=\mathrm{P}<0.0001$. 


\section{Acknowledgments}

This work was supported by the Intramural Research Program of the National Heart, Lung, and Blood Institute (NHLBI) (1ZIAHL006121-04 to JAH). The authors thank the NHLBI Flow Cytometry Core, Dr. Xuefei Ma for providing M2A-GFP mice, Dr. Il-Young Hwang for immunizing mice to prepare GC B cells, and Dr. Christopher J. Alexander for advice on miRNA design.

\section{Competing interests}

We have no competing interests to disclose. 
Figure 1. ICAM-1 co-stimulation promotes the formation of actin arcs at the B cell IS.

(A-F) GFP-F-Tractin-expressing primary $B$ cells on glass coated with anti-IgM alone $(A$, $B, E 1, E 2)$ or with anti-lgM+ICAM-1 (C, D, F1, F2) and imaged using Airyscan (A, C) or TIRF-SIM (B, D, E1, E2, F1, F2). The white arrows in A and B indicate the thin outer rim of dendritic actin in the dSMAC. The blue bars in A-D indicate the pSMAC. E2 and F2 correspond to the boxed regions in $\mathrm{E} 1$ and $\mathrm{F} 1$, respectively. Of note, the cell shown in E1/E2 is representative of $\sim 70 \%$ of anti-IgM stimulated cells, while the cell shown in F1/F2 is representative of $\sim 70 \%$ of anti-IgM+ICAM- 1 stimulated cells. (G) Percent of cells with pSMAC actin arcs ( $\mathrm{N}>67$ cells/condition from 3 experiments). $(\mathrm{H}, \mathrm{I})$ Percent of total synaptic F-actin $(\mathrm{H})$ and percent of total IS footprint (I) contained within the dSMAC, pSMAC and cSMAC portions of the synapse for primary $B$ cells on antiIgG/ICAM-1-coated glass ( $\mathrm{N}=44$ cells/condition from 6 experiments). (J1, J2) GFP-FTractin-expressing A20 B cell on anti-IgG/ICAM-1-coated glass. J2 corresponds to the boxed region in $\mathrm{J} 1$. The magenta arrows in $\mathrm{A}-\mathrm{D}$ and $\mathrm{J} 1$ indicate actin arcs. Scale bars: $10 \mu \mathrm{m}$.

Figure 1- figure supplement 1. Degree of alignment between the actin filaments in the PSMAC of $B$ cells stimulated with anti-IgM alone versus anti-IgM and ICAM-1.

(A1 and A2) Shown are examples of how FibrilTool (29) was used to measure pSMAC actin arc anisotropy by dividing the radially-symmetric PSMAC into 10-12 trapezoidshaped ROls of similar size so as to "linerarize" it (A1, stimulated with anti-lgM alone; A2, stimulated with anti-IgM and ICAM-1) (see also 27). FibrilTool measures how well structures of interest (here actin filaments) within a given region of interest (ROI; here the PSMAC) are arranged in parallel. Anisotropy values range from 0 when the orientation of the structures is completely random to 1.0 when all of the structures are perfectly aligned/parallel to each other. The red lines indicate the average orientation of actin in the ROI. (A3) Measured anisotropy values.

Figure 2. The actin arcs are created by the formin mDia1 acting at the outer edge of the IS.

(A) GFP-F-Tractin-expressing primary B cell on anti-IgG/ICAM-1-coated glass. (B1, B2) Boxed regions in (A). (C1, C2) B1 and B2 with magenta lines applied to highlight linear actin filaments/bundles arising from surface spikes at the IS edge that are contiguous with actin arcs in the pSMAC. (D1, D2) GFP-F-Tractin-expressing primary B cell on antiIgG/ICAM-1-coated glass before (D1) and 6 minutes after SMIFH2 addition (D2). (E) Factin intensity profiles corresponding to the line scans in D1 (blue, before SMIFH2 addition) and D2 (magenta, after SMIFH2 addition). (F1-F4) F-Tractin mNeonGreen expressing A20 B cells transfected with vector only or the indicated mDia1 miRNA constructs and activated on anti-lgG/ICAM-1-coated glass. (G) Ratio of pSMAC to 
dSMAC F-actin ( $\mathrm{N}>20$ cells/condition from 2 experiments). $(\mathrm{H})$ pSMAC F-actin content ( $N=20-26$ cells/condition from 2 experiments). A-C, and F: TIRF-SIM images; $D$ : Airyscan images. Scale bars: $5 \mu \mathrm{m}$ in A, D2, and F1; $2 \mu \mathrm{m}$ in B1.

Figure 2 - figure supplement 1. miRNA-mediated KD of mouse mDia1 in A20 B cells.

(A) Diagram of the plasmid in which mDia1 miRNA sequences are C-terminal to FTractin mNeonGreen. The target sequences used to generate the three mDia1 miRNA knockdown plasmids are indicated in the appendix. Positive transfectants were identified based on the expression of F-Tractin-mNeonGreen and used in subsequent quantitative analyses. (B) Immunoblot of the entire population of A20 B cells that had undergone AMAXA nucleofection with either the F-Tractin-mNeonGreen vector control or with the indicated mDia1 miRNA plasmids. Of note, while the lysates used for immunoblotting were made from samples containing both positive and negative transfectants, only positive transfectants (i.e. mNeonGreen-positive cells) were used for the quantitation presented in Figure 2. (C1 and C2) Representative F-actin images show F-Tractin mNeonGreen expressing A20 B cells transfected with vector only (C1) or with a non-targeting miRNA (C2) and activated on anti-lgG/ICAM-1-coated glass. Scale bars: $10 \mu \mathrm{m}$. (C3) Ratio of pSMAC to dSMAC F-actin ( $\mathrm{N}>38$ cells/condition from 2 experiments). (C4) pSMAC F-actin content ( $\mathrm{N}>38$ cells/condition from 2 experiments). Figure 2 - figure supplement $1 B$ - Source Data 1. Western blots of miRNA-mediated $K D$ of mouse mDia1 in 20 B cells. (A) Entire immunoblot using rabbit anti-mDia1 followed by goat anti-rabbit-HRP secondary. (B) Entire immunoblot using mouse anti- $\beta$ actin-HRP. (C) Blot showing the molecular weight ladder Thermo Fisher Page Ruler Plus. Arrows indicate the relevant bands.

Figure 2 - figure supplement 2. Arp2/3 inhibition shifts the balance between the dSMAC branched actin network and the pSMAC actin arc network.

(A1-A4) TIRF-SIM images of GFP-F-Tractin expressing A20 cells on anti-lgG/ICAM-1coated glass before (A1, A2) and 5 minutes after $C K-666$ addition (A3, A4). A2 and A4 correspond to the boxed regions in $A 1$ and $A 3$, respectively. The magenta and blue bars in $\mathrm{A} 2$ and $\mathrm{A} 4$ correspond to the $\mathrm{dSMAC}$ and pSMAC portions of the synapse, respectively. (B-E) Percent of total synaptic F-actin within each SMAC (B), total pSMAC F-actin content $(C)$, ratio of pSMAC to dSMAC F-actin (D), and ratio of pSMAC to dSMAC area (E) for DMSO-treated and CK-666-treated A20 B cells ( $\mathrm{N}>30$ cells/condition from 3 experiments). Scale bar: $2 \mu \mathrm{m}$ in A4.

Figure 3. Myosin 2A decorates the actin arcs and is required for their concentric organization. 
(A1-A5) Td-Tomato-F-Tractin expressing primary B cell from the M2A-GFP knockin mouse on anti-IgM/ICAM-1-coated glass. A4 and A5 correspond to the boxed regions in $A 1$ and $A 2$, respectively. (B1-B6) Still images at the indicated time points taken from a region within Video 7 of a Td-Tomato-F-Tractin expressing primary B cell from the M2AGFP knockin mouse. Different color arrowheads mark the formation and centripetal movement of individual M2A bipolar filaments (see text for details). (C, D) Phalloidinstained primary $B$ cell from the M2A-GFP knockin mouse on glass coated with anti-IgM alone (C) or with anti-lgM+ICAM-1 (D). (E) Total synaptic M2A content ( $N=91-115$ cells/condition from 3 experiments). ( $F, G)$ GFP-F-Tractin-expressing primary B cells that had been pretreated with DMSO $(F)$ or pnBB $(G)$ for 30 minutes and activated on anti-lgM/ICAM-1-coated glass. $(\mathrm{H})$ Anisotropy of the actin filaments/bundles present within the pSMAC ( $\mathrm{N}=369-423$ ROls from $30-37$ cells from 3 experiments). All panels: TIRF-SIM images. Scale bars: $5 \mu \mathrm{m}$ in A3, D and G; $3 \mu \mathrm{m}$ in A4 and B6, $250 \mathrm{~nm}$ in A5.

Figure 3 - figure supplement 1 . Endogenous M2A decorates the actin arcs in both primary B cells and A20 B cells.

(A) Primary $B$ cell isolated from a mCherry-M2A KI mouse. (B) Primary B cell in which GFP was knocked in at the N-terminus of the M2A heavy chain using ex vivo CRISPR. (C1-C3) GFP-F-Tractin-expressing A20 B cell in which mScarleti was knocked in at the $\mathrm{N}$-terminus of M2A heavy chain using CRISPR. (D1-D3) A20 B cell that was stained with phalloidin and an antibody to the C-terminus of myosin 2A. (E1-E3) Enlargements of the boxed regions in D1-D3. The position of the line scan used to generate the intensity profile in Panel $F$ is shown in white. The white arrows mark the positions in the image that are marked by the black arrows in Panel F. (F) Fluorescence intensity profile for endogenous M2A and F-actin across the line scan shown in Panels E1-E3. The black arrows point to regions of marked overlap between the signals for endogenous M2A and actin arcs. (G1, G2) Shown is the cell spread area (G1) and the synaptic content of M2A normalized for cell spread area (G2) for primary B cells isolated from the GFP-M2A KI mouse ( $\mathrm{N}=91-115$ cells/condition from 3 experiments). Panels $\mathrm{A}, \mathrm{B}, \mathrm{C} 1$ C3, and H: TIRF-SIM images. Panels D1-D3: Airyscan images. All of the cells shown or quantified in Panels A-H were activated on glass coated with anti-IgM and ICAM-1. Scale bars: $5 \mu \mathrm{m}$ in $\mathrm{A}, \mathrm{B}$, and $\mathrm{C} 3 ; 10 \mu \mathrm{m}$ in $\mathrm{D} 3$ and $\mathrm{H} ; 2 \mu \mathrm{m}$ in $\mathrm{E} 3$.

\section{Figure 3 - figure supplement 2. Integrin-dependent traction forces exerted by primary $B$ cells require M2A contractility.}

(A1, A2) Representative primary B cell engaged with a PAA gel coated with anti-lgM (A1) and its force magnitude plot (A2). (B1, B2) Representative, DMSO-treated primary $B$ cell engaged with a PAA gel coated with anti-IgM and ICAM-1 (B1) and its force magnitude plot (B2). (C1, C2) Representative, pnBB-treated primary $B$ cell engaged with a PAA gel coated with anti-IgM and ICAM-1 (C1) and its force magnitude plot (C2). 
(D) Traction forces exerted by $B$ cells under these three conditions ( $N=72-121$ cells/per condition from 3 experiments). Scale bar: $10 \mu \mathrm{m}$.

Figure 4. Actin arcs sweep antigen clusters centripetally.

(A1-A3) Phalloidin-stained (green) primary B cell 15 min after engagement with a PLB containing unlabeled ICAM-1 and limiting anti-lgM (magenta). The white arrows in A1 and A3 mark the actin arcs. (B) Tracks of single anti-IgM microclusters traveling centripetally across the dSMAC (magenta tracks) and pSMAC (green tracks) acquired from Video 9. The white line indicates the outer edge of this cell. (C) Mean speed of single anti-IgM microclusters moving centripetally across the dSMAC and pSMAC ( $N=180-273$ tracks from 3 well-spread cells). (D1-D6) Still images at the indicated time points from Video 10 showing the centripetal movement of actin arcs and a representative anti-lgM microcluster (white arrows) (the center of the synapse is directly below the images). Transparent white lines highlight the actin arcs that moved the microcluster centripetally. (E1-E6) Same as D1-D6 except showing only the anti-IgM microcluster, and indicating its centripetal path in blue. (F) Temporally pseudo-colored, projected image of the anti-IgM microcluster in (D) and (E). (G) Kymograph of the $3 \mu \mathrm{m}$ long paths taken by the microcluster and the actin arcs in (D) and (E) over a period of 400s. The white brackets on the right indicate where actin arcs overlapped with and moved the microcluster, while the magenta brackets indicate where the movement of the microcluster stalled. A: Airyscan images; D-G: TIRF-SIM images. Scale bars: $5 \mu \mathrm{m}$ in $A 3$ and $B ; 300 \mathrm{~nm}$ in $\mathrm{D} 6$ and $F$.

\section{Figure 4 - figure supplement 1 . Centripetal actin flow rates across the dSMAC and PSMAC portions of synapses made by primary B cells and A20 B cells.}

(A1-A3) Shown is a representative, GFP-F-Tractin-expressing primary B cell (A1), a kymograph showing the centripetal flow of F-actin in the dSMAC and PSMAC portions of this cell's synapse over 300s (A2; reconstructed from the blue line in A1; the white arrowheads mark several of the faint diagonals within the dSMAC used to calculate its flow rate), and the average rates of centripetal F-actin actin flow in the dSMAC and pSMAC (A3; 7 measurements per cell for each SMAC from 21 cells over 3 experiments, presented as standard error of the means). (B1-B3) Same as A1-A3 except using A20 B cells ( $\mathrm{N}=14$ cells from 3 experiments). In every case the cells were activated using glass coated with anti-Igs and ICAM-1. All panels: TIRF-SIM. Scale bars: $10 \mu \mathrm{m}$.

\section{Figure 5. Integrin ligation-dependent IS formation requires myosin 2A contractility.}

(A1-A3) DMSO-treated, phalloidin-stained primary B cells 15 min after engagement with a PLB containing ICAM-1 and limiting anti-IgM. (B1-B3) Same as A1-A3 except the B 
cells were treated with pnBB. (C1-C3) Images of a representative, DMSO-treated primary $B$ cell (white arrows mark actin arcs). (D1-D3) Images of a representative, pnBB-treated primary B cell. (E) Percent of cells exhibiting centralized, partially centralized and non-centralized antigen (see Figure 5 - figure supplement 1D1-D3 for representative examples of these three types of antigen distribution) ( $\mathrm{N}=126-144$ cells/condition from 3 experiments). (F) Percent of total synaptic antigen in the cSMAC ( $\mathrm{N}=81-86$ cells/condition from 3 experiments). (G) Antigen cluster size as a function of normalized distance from the cSMAC center $(\mathrm{N}=113-144$ cells/condition from 3 experiments). $(\mathrm{H})$ Total synaptic antigen content ( $\mathrm{N}=56-62$ cells/condition from 3 experiments). All panels: Airyscan images. Scale bars: $10 \mu \mathrm{m}$ in A1, B1, A3, and B3; 5 $\mu \mathrm{m}$ in D3.

\section{Figure 5 - figure supplement 1. ICAM-1 co-stimulation promotes antigen centralization and IS formation when antigen is limiting.}

(A1-A3) Representative, phalloidin-stained primary B cell 15 min after engagement with a PLB containing fluorescent anti-IgM at high density. (B1-B3) Phalloidin-stained primary $B$ cells 15 min after engagement with a PLB containing a limiting amount of anti-IgM. (C1-C3) Same as B1-B3 except the PLB also contained ICAM-1. (D1-D3) Representative images of centralized, partially centralized and non-centralized antigen. (E) Percent of cells exhibiting the three types of antigen distribution shown in D1-D3 ( $N=151$ cells/condition from 4 experiments). ( $F)$ Percent of total synaptic antigen in the cSMAC ( $\mathrm{N}=66-68$ cells/condition from 3 experiments). ( $\mathrm{G})$ Antigen cluster size as a function of normalized distance from the cSMAC center ( $\mathrm{N}=62-69$ cells/condition from 3 experiments). $(\mathrm{H})$ Total synaptic antigen content $(\mathrm{N}=83-87$ cells/condition from 3 experiments). All panels: Airyscan images. Scale bars: $10 \mu \mathrm{m}$.

\section{Figure 5 - figure supplement 2. M2A contractility potentiates antigen centralization even when antigen density is high.}

(A1-A3) Phalloidin-stained, DMSO-treated primary B cells $15 \mathrm{~min}$ after engagement with a PLB containing high density anti-IgM. (B1-B3) Same as A1-A3 except the cells were treated with pnBB. (C) Percent of cells exhibiting centralized, partially centralized and non-centralized antigen ( $\mathrm{N}=137-198$ cells/condition from 3 experiments). (D) Percent of total synaptic antigen in the cSMAC ( $N=91-121$ cells/condition from 3 experiments). (E) Antigen cluster size as a function of normalized distance from the cSMAC center ( $N=86$ 130 cells/condition from 3 experiments). All panels: Airyscan images. Scale bars: 10 $\mu \mathrm{m}$.

Figure 6. Myosin 2A contractility promotes BCR signaling.

(A1-A4) DMSO-treated primary B cell 10 min after engagement with a PLB containing ICAM-1 and limiting anti-IgM, and stained for F-actin and P-CD79a. (B1-B4) Same as 
A1-A4 except the B cell was treated with pnBB. (C) Synaptic P-CD79a content $(\mathrm{N}=55-$ 81 cells/condition from 3 experiments). (D1-D4) DMSO-treated primary B cell $10 \mathrm{~min}$ after engagement with a PLB containing ICAM-1 and limiting anti-IgM, and stained for F-actin and P-CD19. (E1-E4) Same as D1-D4 except the cell was treated with pnBB. (F) Synaptic P-CD19 content ( $\mathrm{N}=115-140$ cells/condition from 3 experiments). (G)

Fluorescence intensities across synapses for P-CD19 (red), antigen (grey), and F-actin (green) in B cells treated with DMSO ( $\mathrm{N}=22$ cells from 2 experiments). The position of the pSMAC is highlighted in blue. $(\mathrm{H})$ Same as $\mathrm{G}$ except the cells were treated with pnBB ( $\mathrm{N}=16$ cells from 2 experiments). All panels: Airyscan images. Scale bars: $5 \mu \mathrm{m}$ in $\mathrm{B} 4 ; 3 \mu \mathrm{m}$ in $\mathrm{E} 4$.

Figure 6 - figure supplement 1. Myosin 2A contractility promotes BCR signaling.

(A) Synaptic content of P-CD79a in DMSO-treated or pnBB-treated primary B cells 5 minutes after engaging PLBs containing ICAM-1 and a limiting amount of anti-IgM. (B) Same as Panel A except showing the synaptic content of CD-79a at 5 and 10 minutes. (C) Same as Panel A except showing the synaptic content of CD-19 at 10 minutes. $\mathrm{N}=41-53$ cells/condition from 3 experiments.

\section{Figure 7. GC B cells make actomyosin arcs.}

(A1-A3) Phalloidin-stained primary GC B cell from the M2A-GFP knockin mouse on antiIgM/anti-lgG/ICAM-1-coated glass. White arrows mark the actomyosin arcs. (B) Percent of cells on glass that did or did not show M2A enrichment in the pSMAC $(N=140$ cells from 4 experiments). (C) Phalloidin-stained primary GC B cell from the M2A-GFP knockin mouse 15 min after engagement with a PLB containing anti-IgM, anti-IgG, and ICAM-1. (D) Percent of cells on PLBs that did or did not show M2A enrichment in the pSMAC ( $\mathrm{N}=89$ cells from 4 experiments). (E1-E4) Representative images of the three types of anti-Ig distribution exhibited by GC B cells 15 min after engagement with a PLB containing anti-IgG and ICAM-1 (cell outlines are shown in blue). (F) Percent of GC cells displaying the three types of anti-lg distribution shown in $E 1-E 4$ ( $N=157$ cells from 6 experiments). All panels: TIRF-SIM images. Scale bars: $5 \mu \mathrm{m}$ in A3; $3 \mu \mathrm{m}$ in $\mathrm{C} 4$ and E4.

Figure 7 - figure supplement 1. Distribution of GFP-M2A in synapses formed by PLB-engaged GC B cells. (A1-A3) Shown are representative images of the distribution of GFP-M2A (green) and anti-Igs (magenta) in GC B cell synapses exhibiting centralized antigen clusters (A1), microclusters (A2) or peripheral antigen clusters (A3). See also Movies 12 and 13. All panels: TIRF-SIM images. Scale bars: $5 \mu \mathrm{m}$.

\section{Video Legends}

Videos $1 \mathrm{~A}$ and $1 \mathrm{~B}$ 
Representative primary B cells expressing GFP-F-Tractin on glass coated with anti-lgM that were imaged every 3s for 120s using Airyscan (1A) and TIRF-SIM (1B). Played back at $10 \mathrm{fps}$. Scale bar: $5 \mu \mathrm{m}$.

\section{Videos 2A and 2B}

Representative primary B cells expressing GFP-F-Tractin on glass coated with anti-lgM and ICAM-1 that were imaged every 2s for 120s using Airyscan (2A) and every 5 s for 600s using TIRF-SIM (2B). Played back at $10 \mathrm{fps}$. Scale bars: $5 \mu \mathrm{m}$.

\section{Videos $3 A$ and $3 B$}

A representative primary $B$ cell expressing GFP-F-Tractin on glass coated with anti-IgM and ICAM-1 that was imaged every 3s for 300s using TIRF-SIM (3A). A magnified view of the region boxed in white in $3 A$ is shown in $3 B$. Played back at $10 \mathrm{fps}$. Scale bars: 5 $\mu \mathrm{m}(3 \mathrm{~A}), 1 \mu \mathrm{m}(3 \mathrm{~B})$.

\section{Video 4}

A representative $A 20 \mathrm{~B}$ cell expressing mEos-actin on glass coated with anti-IgG and ICAM-1 that was imaged every $1.8 \mathrm{~s}$ for 70 s using Airyscan. Played back at $7 \mathrm{fps}$. Scale bar: $5 \mu \mathrm{m}$.

\section{Videos $5 A$ and $5 B$}

A representative A20 B cell expressing GFP-F-Tractin on glass coated with anti-IgG and ICAM-1 that was imaged every 1.5 s for 120 s using TIRF-SIM (5A). A representative A20 B cell in which we had inserted mScarleti at the N-terminus of M2A using CRISPR (magenta) that was transfected with GFP-F-Tractin (green), activated on glass coated with anti-IgG and ICAM-1, and imaged every 3s for 120s using TIRF-SIM (5B). Played back at $10 \mathrm{fps}$. Scale bars: $5 \mu \mathrm{m}$.

\section{Video 6}

A representative primary $B$ cell from a M2A-GFP knockin mouse expressing TdTomato-F-Tractin on glass coated with anti-IgM and ICAM-1 that was imaged every $3 \mathrm{~s}$ for 300s using TIRF-SIM. Played back at $10 \mathrm{fps}$. Scale bar: $5 \mu \mathrm{m}$.

\section{Video 7}

A magnified view of a region within Video 6. The applied arrowheads mark various aspects of M2A filament assembly and organization as explained in the text for Figure 3B1-B6. Played back at $8 \mathrm{fps}$. Scale bar: $1 \mu \mathrm{m}$.

\section{Videos $8 \mathrm{~A}$ and $8 \mathrm{~B}$}

Representative primary B cells expressing GFP-F-Tractin on PLBs containing anti-IgM and ICAM-1 (8A) or anti-IgM alone (8B) that were imaged every 5s for 300s using TIRFSIM and played back at $8 \mathrm{fps}$. Scale bar: $5 \mu \mathrm{m}$. 


\section{Video 9}

A representative primary $B$ cell on a PLB containing fluorescent anti-IgM (white) and unlabeled ICAM- 1 that was imaged every $5 \mathrm{~s}$ for $345 \mathrm{~s}$ using TIRF-SIM. Played back at $10 \mathrm{fps}$. Scale bar: $5 \mu \mathrm{m}$.

\section{Video 10}

A region within the $\mathrm{PSMAC}$ of a representative primary $\mathrm{B}$ cell expressing GFP-F-Tractin (green), engaged with a PLB containing fluorescent anti-lgM (red) and unlabeled ICAM1 , and imaged every $5 \mathrm{~s}$ for 400 s using TIRF-SIM. The applied white lines mark actin arcs that are sweeping an antigen cluster centripetally, as explained in the text for Fig ure 4D1-D6. The inward tracks of this cluster and two other clusters are then shown in blue, green and red, respectively. Played back at $10 \mathrm{fps}$. Scale bar: $1 \mu \mathrm{m}$.

\section{Video 11}

A representative primary GC B cell isolated from the GFP-M2A knockin mouse that was stained with CellMask ${ }^{\mathrm{TM}}$ Deep Red (magenta) to label its plasma membrane, activated on glass coated with anti-IgM and ICAM-1, and imaged every 5 s for 300 s using TIRFSIM. The first 11 frames show a still image of the magenta cell membrane. Played back at $10 \mathrm{fps}$. Scale bar: $5 \mu \mathrm{m}$.

\section{Video 12}

A representative primary GC B cell isolated from the GFP-M2A knockin mouse that exhibited centralized antigen clusters on a PLB containing anti-Igs (magenta), imaged every $5 \mathrm{~s}$ for 300 s using TIRF-SIM, and played back at $7 \mathrm{fps}$. Scale bar: $3 \mu \mathrm{m}$.

\section{Video 13}

A representative primary GC B cell isolated from the GFP-M2A knockin mouse that exhibited peripheral antigen clusters on a PLB containing anti-Igs (magenta), imaged every 5 s for 180 s using TIRF-SIM, and played back at $7 \mathrm{fps}$. Scale bar: $5 \mu \mathrm{m}$. 


\section{Appendix}

\begin{tabular}{|c|c|c|c|c|}
\hline \multicolumn{5}{|c|}{ Key Resources Table } \\
\hline $\begin{array}{l}\text { Reagent type } \\
\text { (species) or } \\
\text { resource }\end{array}$ & Designation & $\begin{array}{l}\text { Source or } \\
\text { reference }\end{array}$ & Identifiers & $\begin{array}{l}\text { Additional } \\
\text { information }\end{array}$ \\
\hline $\begin{array}{l}\text { strain, strain } \\
\text { background } \\
\text { (Mus } \\
\text { musculus) }\end{array}$ & C57BL/6 & $\begin{array}{l}\text { Jackson } \\
\text { Laboratories }\end{array}$ & $\begin{array}{l}\text { Cat \#002595 } \\
\text { RRID:MGI:565 } \\
6552\end{array}$ & \\
\hline $\begin{array}{l}\text { strain, strain } \\
\text { background } \\
\text { (Mus } \\
\text { musculus) }\end{array}$ & M2A-GFP KI & $\begin{array}{l}\text { Robert } \\
\text { Adelstein, } \\
\text { NHLBI/NIH }\end{array}$ & & \\
\hline $\begin{array}{l}\text { Cell line (Mus } \\
\text { musculus) }\end{array}$ & A20 & $\begin{array}{l}\text { American Type } \\
\text { Culture } \\
\text { Collection }\end{array}$ & $\begin{array}{l}\text { ATCC® TIB- } \\
208^{\text {TM }} \\
\text { RRID:CVCL_1 } \\
940\end{array}$ & $\operatorname{lgG}^{+} B$ cell line \\
\hline $\begin{array}{l}\text { Recombinant } \\
\text { DNA reagent }\end{array}$ & GFP-F-Tractin & $\begin{array}{l}\text { Michael Schell } \\
\text { (Uniformed } \\
\text { Services } \\
\text { University, } \\
\text { Maryland) }\end{array}$ & & \\
\hline $\begin{array}{l}\text { Recombinant } \\
\text { DNA reagent }\end{array}$ & $\begin{array}{l}\text { tdTomato-F- } \\
\text { Tractin }\end{array}$ & $\begin{array}{l}\text { Michael Schell } \\
\text { (Uniformed } \\
\text { Services } \\
\text { University, } \\
\text { Maryland) }\end{array}$ & & \\
\hline $\begin{array}{l}\text { Chemical } \\
\text { compound, } \\
\text { drug }\end{array}$ & $\begin{array}{l}\text { Alexa Fluor } \\
488 \text { Phalloidin }\end{array}$ & $\begin{array}{l}\text { Thermo Fisher } \\
\text { Scientific }\end{array}$ & Cat \#A12379 & $\begin{array}{l}\text { Fluorescence } \\
\text { labeling } \\
(1: 500)\end{array}$ \\
\hline $\begin{array}{l}\text { Chemical } \\
\text { compound, } \\
\text { drug }\end{array}$ & $\begin{array}{l}\text { Alexa Fluor } \\
568 \text { Phalloidin }\end{array}$ & $\begin{array}{l}\text { Thermo Fisher } \\
\text { Scientific }\end{array}$ & Cat \#A12380 & $\begin{array}{l}\text { Fluorescence } \\
\text { labeling } \\
(1: 500)\end{array}$ \\
\hline $\begin{array}{l}\text { Chemical } \\
\text { compound, } \\
\text { drug }\end{array}$ & $\begin{array}{l}\text { CellMask }^{\mathrm{TM}} \\
\text { Deep Red } \\
\text { Plasma } \\
\text { Membrane } \\
\text { Stain }\end{array}$ & $\begin{array}{l}\text { Thermo Fisher } \\
\text { Scientific }\end{array}$ & Cat \#C10046 & $\begin{array}{l}\text { Cell labeling } \\
(1: 10000)\end{array}$ \\
\hline $\begin{array}{l}\text { Chemical } \\
\text { compound, } \\
\text { drug }\end{array}$ & DMSO & Millipore Sigma & Cat \#D4540 & \\
\hline
\end{tabular}




\begin{tabular}{|c|c|c|c|c|}
\hline $\begin{array}{l}\text { Chemical } \\
\text { compound, } \\
\text { drug }\end{array}$ & SMIFH2 & Millipore Sigma & Cat \#344092 & $25 \mu \mathrm{M}$ \\
\hline $\begin{array}{l}\text { Chemical } \\
\text { compound, } \\
\text { drug }\end{array}$ & CK-666 & Millipore Sigma & Cat \#182515 & $100 \mu \mathrm{M}$ \\
\hline $\begin{array}{l}\text { Chemical } \\
\text { compound, } \\
\text { drug }\end{array}$ & $\begin{array}{l}\text { (S)-nitro- } \\
\text { blebbistatin } \\
\text { (pnBB) }\end{array}$ & $\begin{array}{l}\text { Cayman } \\
\text { Chemicals }\end{array}$ & Cat \#24171 & $25 \mu \mathrm{M}$ \\
\hline $\begin{array}{l}\text { Chemical } \\
\text { compound, } \\
\text { drug }\end{array}$ & $\begin{array}{l}\text { Para-amino } \\
\text { blebbistatin }\end{array}$ & $\begin{array}{l}\text { Cayman } \\
\text { Chemicals }\end{array}$ & Cat \#22699 & $25 \mu \mathrm{M}$ \\
\hline $\begin{array}{l}\text { Chemical } \\
\text { compound, } \\
\text { drug }\end{array}$ & $\begin{array}{l}\text { Zombie Yellow } \\
\text { viability stain }\end{array}$ & Biolegend & Cat \#423103 & $\begin{array}{l}\text { Dead cell } \\
\text { staining } \\
(1: 300)\end{array}$ \\
\hline $\begin{array}{l}\text { Chemical } \\
\text { compound, } \\
\text { drug }\end{array}$ & $\begin{array}{l}\text { 18:1 Biotinyl } \\
\text { Cap PE IN } \\
\text { CHLOROFOR } \\
\text { M 1,2-dioleoyl- } \\
\text { sn-glycero-3- } \\
\text { phosphoethan } \\
\text { olamine-N-(cap } \\
\text { biotinyl) }\end{array}$ & $\begin{array}{l}\text { Avanti Polar } \\
\text { Lipids }\end{array}$ & Cat \#870273C & \\
\hline $\begin{array}{l}\text { Chemical } \\
\text { compound, } \\
\text { drug }\end{array}$ & $\begin{array}{l}18: 1 \text { DGS- } \\
\text { NTA(Ni) in } \\
\text { Chloroform } \\
\text { 1,2-dioleoyl-sn- } \\
\text { glycero-3-[(N- } \\
\text { (5-amino-1- } \\
\text { carboxypentyl) } \\
\text { iminodiacetic } \\
\text { acid)succinyl] } \\
\text { (nickel salt) }\end{array}$ & $\begin{array}{l}\text { Avanti Polar } \\
\text { Lipids }\end{array}$ & Cat \#790404C & \\
\hline $\begin{array}{l}\text { Chemical } \\
\text { compound, } \\
\text { drug }\end{array}$ & $\begin{array}{l}\text { 18:1 (9-Cis) PC } \\
\text { (DOPC) in } \\
\text { CHLOROFOR } \\
\text { M 1,2-dioleoyl- } \\
\text { sn-glycero-3- } \\
\text { phosphocholin } \\
\text { e }\end{array}$ & $\begin{array}{l}\text { Avanti Polar } \\
\text { Lipids }\end{array}$ & Cat \#850375C & \\
\hline $\begin{array}{l}\text { Chemical } \\
\text { compound, } \\
\text { drug }\end{array}$ & $\begin{array}{l}\text { TransFluoSphe } \\
\text { res }(633 / 720)\end{array}$ & $\begin{array}{l}\text { Thermo Fisher } \\
\text { Scientific }\end{array}$ & Cat \#T8870 & \\
\hline
\end{tabular}




\begin{tabular}{|c|c|c|c|c|}
\hline Other & $\begin{array}{l}\text { Escherichia } \\
\text { coli O111:B4 } \\
\text { LPS }\end{array}$ & Millipore Sigma & Cat \#L2630 & $\begin{array}{l}\text { Cell culture } 2.5 \\
\mu \mathrm{g} / \mathrm{ml}\end{array}$ \\
\hline $\begin{array}{l}\text { Biological } \\
\text { sample (Ovis } \\
\text { aries) }\end{array}$ & $\begin{array}{l}\text { Sheep's red } \\
\text { blood cells }\end{array}$ & $\begin{array}{l}\text { Innovative } \\
\text { Research Novi }\end{array}$ & $\begin{array}{l}\text { Cat } \\
\# I S H R B C 100 P \\
15 M L\end{array}$ & $\begin{array}{l}\text { Injection } 2 \times 10^{8} \\
\text { cells }\end{array}$ \\
\hline Antibody & $\begin{array}{l}\text { Alexa Fluor } \\
488- \\
\text { conjugated } \\
\text { goat, anti- } \\
\text { rabbit, } \\
\text { polyclonal }\end{array}$ & $\begin{array}{l}\text { Jackson } \\
\text { ImmunoResear } \\
\text { ch }\end{array}$ & $\begin{array}{l}\text { Cat \#111-545- } \\
003 \\
\text { RRID:AB_2338 } \\
046\end{array}$ & $\begin{array}{l}\text { Immunofluores } \\
\text { cence }(1: 500)\end{array}$ \\
\hline Antibody & $\begin{array}{l}\text { Alexa Fluor } \\
594 \text { conjugated } \\
\text { goat, anti- } \\
\text { rabbit, } \\
\text { polyclonal }\end{array}$ & $\begin{array}{l}\text { Jackson } \\
\text { ImmunoResear } \\
\text { ch }\end{array}$ & $\begin{array}{l}\text { Cat \#111-585- } \\
003 \\
\text { RRID:AB_2338 } \\
059\end{array}$ & $\begin{array}{l}\text { Immunofluores } \\
\text { cence }(1: 500)\end{array}$ \\
\hline Antibody & $\begin{array}{l}\text { Alexa Fluor } \\
647- \\
\text { conjugated } \\
\text { goat, anti- } \\
\text { rabbit, } \\
\text { polyclonal }\end{array}$ & $\begin{array}{l}\text { Jackson } \\
\text { ImmunoResear } \\
\text { ch }\end{array}$ & $\begin{array}{l}\text { Cat \#111-605- } \\
003 \\
\text { RRID:AB_2338 } \\
072\end{array}$ & $\begin{array}{l}\text { Immunofluores } \\
\text { cence }(1: 500)\end{array}$ \\
\hline Antibody & $\begin{array}{l}\text { Goat anti- } \\
\text { mouse lgG, } \\
\text { Fcy fragment } \\
\text { specific, } \\
\text { polyclonal }\end{array}$ & $\begin{array}{l}\text { Jackson } \\
\text { ImmunoResear } \\
\text { ch }\end{array}$ & $\begin{array}{l}\text { Cat \#115-005- } \\
008 \\
\text { RRID:AB_2338 } \\
449\end{array}$ & $\begin{array}{l}\text { Coverslip } \\
\text { coating } 2.5 \\
\mu \mathrm{g} / \mathrm{cm}^{2}\end{array}$ \\
\hline Antibody & $\begin{array}{l}\text { Goat anti- } \\
\text { mouse IgM, } \mu- \\
\text { chain specific, } \\
\text { polyclonal }\end{array}$ & $\begin{array}{l}\text { Jackson } \\
\text { ImmunoResear } \\
\text { ch }\end{array}$ & $\begin{array}{l}\text { Cat \#115-005- } \\
020 \\
\text { RRID:AB_2338 } \\
450\end{array}$ & $\begin{array}{l}\text { Coverslip } \\
\text { coating } 2.5 \\
\mu \mathrm{g} / \mathrm{cm}^{2}\end{array}$ \\
\hline Antibody & $\begin{array}{l}\text { Goat anti- } \\
\text { Rabbit IgG } \\
(\mathrm{H}+\mathrm{L}) \text { Poly- } \\
\text { HRP, } \\
\text { polyclonal }\end{array}$ & Thermo Fisher & $\begin{array}{l}\text { Cat \#32260 } \\
\text { RRID:AB_1965 } \\
959\end{array}$ & $\begin{array}{l}\text { Western blot } \\
(1: 3000)\end{array}$ \\
\hline Antibody & $\begin{array}{l}\text { Rabbit anti- } \\
\text { DIAPH1, } \\
\text { polyclonal }\end{array}$ & Thermo Fisher & $\begin{array}{l}\text { Cat \#PA5- } \\
27607 \\
\text { RRID:AB_2545 } \\
083\end{array}$ & $\begin{array}{l}\text { Western blot } \\
(1: 250)\end{array}$ \\
\hline Antibody & $\begin{array}{l}\beta \text {-Actin } \\
\text { Antibody (C4), }\end{array}$ & Santa Cruz & $\begin{array}{l}\text { Cat \#SC- } \\
47778 \text { HRP }\end{array}$ & $\begin{array}{l}\text { Western blot } \\
(1: 5000)\end{array}$ \\
\hline
\end{tabular}




\begin{tabular}{|c|c|c|c|c|}
\hline & $\begin{array}{l}\text { mouse } \\
\text { monoclonal }\end{array}$ & & $\begin{array}{l}\text { RRID:AB_2714 } \\
189\end{array}$ & \\
\hline Antibody & $\begin{array}{l}\text { Rabbit anti- } \\
\text { CD79a, } \\
\text { polyclonal }\end{array}$ & $\begin{array}{l}\text { Cell Signaling } \\
\text { Technologies }\end{array}$ & $\begin{array}{l}\text { Cat \#3351 } \\
\text { RRID:AB_2075 } \\
745\end{array}$ & $\begin{array}{l}\text { Immunofluores } \\
\text { cence }(1: 250)\end{array}$ \\
\hline Antibody & $\begin{array}{l}\text { Rabbit anti- } \\
\text { phospho- } \\
\text { CD79a, } \\
\text { polyclonal }\end{array}$ & $\begin{array}{l}\text { Cell Signaling } \\
\text { Technologies }\end{array}$ & $\begin{array}{l}\text { Cat \#5173 } \\
\text { RRID:AB_1069 } \\
4763\end{array}$ & $\begin{array}{l}\text { Immunofluores } \\
\text { cence }(1: 250)\end{array}$ \\
\hline Antibody & $\begin{array}{l}\text { Rabbit anti- } \\
\text { CD19, } \\
\text { polyclonal }\end{array}$ & $\begin{array}{l}\text { Cell Signaling } \\
\text { Technologies }\end{array}$ & $\begin{array}{l}\text { Cat \#3574 } \\
\text { RRID:AB_2275 } \\
523\end{array}$ & $\begin{array}{l}\text { Immunofluores } \\
\text { cence }(1: 250)\end{array}$ \\
\hline Antibody & $\begin{array}{l}\text { Rabbit anti- } \\
\text { phospho- } \\
\text { CD19, } \\
\text { polyclonal }\end{array}$ & $\begin{array}{l}\text { Cell Signaling } \\
\text { Technologies }\end{array}$ & $\begin{array}{l}\text { Cat \#3571 } \\
\text { RRID:AB_2072 } \\
836\end{array}$ & $\begin{array}{l}\text { Immunofluores } \\
\text { cence }(1: 250)\end{array}$ \\
\hline Antibody & $\begin{array}{l}\text { Rabbit anti- } \\
\text { M2A, } \\
\text { polyclonal }\end{array}$ & Millipore Sigma & $\begin{array}{l}\text { Cat \#M8064 } \\
\text { RRID:AB_2606 } \\
73\end{array}$ & $\begin{array}{l}\text { Immunofluores } \\
\text { cence }(1: 200)\end{array}$ \\
\hline Antibody & $\begin{array}{l}\text { TruStain FcX } \\
\text { PLUS (anti- } \\
\text { mouse } \\
\text { CD16/32) } \\
\text { antibody, rat } \\
\text { monoclonal }\end{array}$ & Biolegend & $\begin{array}{l}\text { Cat \#156604 } \\
\text { RRID:AB_2783 } \\
138\end{array}$ & $\begin{array}{l}\text { FcR block } \\
\left(0.25 \mu g / 10^{6}\right. \\
\text { cells })\end{array}$ \\
\hline Antibody & $\begin{array}{l}\text { Pacific Blue }{ }^{\mathrm{TM}} \\
\text { anti-mouse } \\
\text { CD38, rat } \\
\text { monoclonal }\end{array}$ & Biolegend & $\begin{array}{l}\text { Cat \#102719 } \\
\text { RRID:AB_1061 } \\
3289\end{array}$ & FACS (1:100) \\
\hline Antibody & $\begin{array}{l}\text { PerCP/Cyanin } \\
\text { e5.5 anti- } \\
\text { mouse/human } \\
\text { CD45R/B220, } \\
\text { rat monoclonal }\end{array}$ & Biolegend & $\begin{array}{l}\text { Cat \#103235 } \\
\text { RRID:AB_8933 } \\
56\end{array}$ & FACS (1:100) \\
\hline Antibody & $\begin{array}{l}\text { APC anti- } \\
\text { MU/HU GL7 } \\
\text { antigen, rat } \\
\text { monoclonal }\end{array}$ & Biolegend & $\begin{array}{l}\text { Cat \#144617 } \\
\text { RRID:AB_2800 } \\
674\end{array}$ & FACS (1:200) \\
\hline $\begin{array}{l}\text { Recombinant } \\
\text { DNA reagent }\end{array}$ & $\begin{array}{l}\text { mNeonGreen- } \\
\text { F-Tractin }\end{array}$ & This paper & & \\
\hline $\begin{array}{l}\text { Sequence- } \\
\text { based reagent }\end{array}$ & $\begin{array}{l}\text { Non-Targeting } \\
\text { miRNA }\end{array}$ & This paper & miRNA & $\begin{array}{l}\text { ACCTAAGGTT } \\
\text { AAGTCGCCC } \\
\text { TCG }\end{array}$ \\
\hline
\end{tabular}




\begin{tabular}{|c|c|c|c|c|}
\hline $\begin{array}{l}\text { Sequence- } \\
\text { based reagent }\end{array}$ & $\begin{array}{l}\text { mDia1 miRNA } \\
\# 1\end{array}$ & This paper & miRNA & $\begin{array}{l}\text { CAGCATGGC } \\
\text { TAAATGGTCA }\end{array}$ \\
\hline $\begin{array}{l}\text { Sequence- } \\
\text { based reagent }\end{array}$ & $\begin{array}{l}\text { mDia1 miRNA } \\
\text { \#2 }\end{array}$ & This paper & miRNA & $\begin{array}{l}\text { GGGTCCGTT } \\
\text { TGCTGCCTTA }\end{array}$ \\
\hline $\begin{array}{l}\text { Sequence- } \\
\text { based reagent }\end{array}$ & $\begin{array}{l}\text { mDia1 miRNA } \\
\# 3\end{array}$ & This paper & miRNA & $\begin{array}{l}\text { GGGTAGCAA } \\
\text { TGCTGTGTTT }\end{array}$ \\
\hline $\begin{array}{l}\text { Sequence- } \\
\text { based reagent }\end{array}$ & MYH9 sgRNA & Synthego & sgRNA & $\begin{array}{l}\text { AAACUUCAU } \\
\text { CAAUAACCC } \\
\text { GC }\end{array}$ \\
\hline $\begin{array}{l}\text { Recombinant } \\
\text { DNA reagent }\end{array}$ & $\begin{array}{l}\text { Mouse GFP- } \\
\text { M2A }\end{array}$ & $\begin{array}{l}\text { Jordan Beach } \\
\text { (Loyola } \\
\text { University, } \\
\text { Chicago) }\end{array}$ & & $\begin{array}{l}\text { CRISPR GFP- } \\
\text { M2A template }\end{array}$ \\
\hline $\begin{array}{l}\text { Recombinant } \\
\text { DNA reagent }\end{array}$ & $\begin{array}{l}\text { Mouse } \\
\text { Scarleti-M2A }\end{array}$ & $\begin{array}{l}\text { Jordan Beach } \\
\text { (Loyola } \\
\text { University, } \\
\text { Chicago) }\end{array}$ & & $\begin{array}{l}\text { mScarleti- } \\
\text { CRISPR M2A } \\
\text { template }\end{array}$ \\
\hline $\begin{array}{l}\text { Peptide, } \\
\text { recombinant } \\
\text { protein }\end{array}$ & $\begin{array}{l}\text { Alt-R® S.p. } \\
\text { HiFi Cas9 } \\
\text { Nuclease V3 }\end{array}$ & IDT & Cat \#1081060 & \\
\hline $\begin{array}{l}\text { Peptide, } \\
\text { recombinant } \\
\text { protein }\end{array}$ & BAFF & R\&D Systems & $\begin{array}{l}\text { Cat \#8876-BF- } \\
010\end{array}$ & $\begin{array}{l}\text { Cell culture } 5 \\
\mathrm{ng} / \mathrm{ml}\end{array}$ \\
\hline $\begin{array}{l}\text { peptide, } \\
\text { recombinant } \\
\text { protein }\end{array}$ & Streptavidin & $\begin{array}{l}\text { Millipore } \\
\text { Sigma }\end{array}$ & Cat \#189730 & \\
\hline $\begin{array}{l}\text { peptide, } \\
\text { recombinant } \\
\text { protein }\end{array}$ & $\begin{array}{l}\text { Mouse } \\
\text { histidine- } \\
\text { tagged ICAM- } \\
1\end{array}$ & $\begin{array}{l}\text { Sino } \\
\text { Biological }\end{array}$ & $\begin{array}{l}\text { Cat \#50440- } \\
\text { M08H }\end{array}$ & \\
\hline $\begin{array}{l}\text { Commercial } \\
\text { assay or kit }\end{array}$ & $\begin{array}{l}\text { Nucleofector } \\
\text { Kit V }\end{array}$ & Lonza & $\begin{array}{l}\text { Cat \#VCA- } \\
1003\end{array}$ & \\
\hline $\begin{array}{l}\text { Commercial } \\
\text { assay or kit }\end{array}$ & $\begin{array}{l}\text { In-Fusion HD } \\
\text { Cloning }\end{array}$ & Takara & Cat \#638911 & \\
\hline $\begin{array}{l}\text { Commercial } \\
\text { assay or kit }\end{array}$ & $\begin{array}{l}\text { Mini-extruder } \\
\text { kit }\end{array}$ & $\begin{array}{l}\text { Avanti Polar } \\
\text { Lipids }\end{array}$ & Cat \#610000 & \\
\hline $\begin{array}{l}\text { Commercial } \\
\text { assay or kit }\end{array}$ & $\begin{array}{l}\text { Sticky-Slide } \\
\text { VI0.4 Luer } \\
\text { closed } \\
\text { chambers }\end{array}$ & Ibidi & Cat \#80608 & \\
\hline $\begin{array}{l}\text { Commercial } \\
\text { assay or kit }\end{array}$ & $\begin{array}{l}\text { Alexa Fluor }{ }^{\mathrm{TM}} \\
647 \text { Antibody } \\
\text { Labeling Kit }\end{array}$ & $\begin{array}{l}\text { Thermo } \\
\text { Fisher } \\
\text { Scientific }\end{array}$ & Cat \#A20186 & \\
\hline
\end{tabular}




\begin{tabular}{|c|c|c|c|c|}
\hline $\begin{array}{l}\text { Commercial } \\
\text { assay or kit }\end{array}$ & $\begin{array}{l}\text { EZ-Link }{ }^{\mathrm{TM}} \\
\text { Micro Sulfo- } \\
\text { NHS- } \\
\text { Biotinylation } \\
\text { Kit }\end{array}$ & $\begin{array}{l}\text { Thermo } \\
\text { Fisher } \\
\text { Scientific }\end{array}$ & Cat \#21925 & \\
\hline $\begin{array}{l}\text { Software, } \\
\text { algorithm }\end{array}$ & ImageJ & $\mathrm{NIH}$ & & \\
\hline $\begin{array}{l}\text { Software, } \\
\text { algorithm }\end{array}$ & FIJI & (97) & $\begin{array}{l}\text { RRID:SCR_00 } \\
2285\end{array}$ & $\begin{array}{l}\text { https://imagej.n } \\
\text { et/Fiji }\end{array}$ \\
\hline $\begin{array}{l}\text { Software, } \\
\text { algorithm }\end{array}$ & Softworx & $\begin{array}{l}\text { Applied } \\
\text { Precision Ltd.; } \\
\text { GE } \\
\text { Healthcare } \\
\text { Life Sciences }\end{array}$ & $\begin{array}{l}\text { RRID:SCR_01 } \\
9157\end{array}$ & \\
\hline $\begin{array}{l}\text { Software, } \\
\text { algorithm }\end{array}$ & ZEN & Zeiss & $\begin{array}{l}\text { RRID:SCR_01 } \\
8163\end{array}$ & \\
\hline $\begin{array}{l}\text { Software, } \\
\text { algorithm }\end{array}$ & FibrilTool & (29) & $\begin{array}{l}\text { RRID:SCR_01 } \\
6773\end{array}$ & \\
\hline $\begin{array}{l}\text { Software, } \\
\text { algorithm }\end{array}$ & $\begin{array}{l}\text { BLOCK-iT } \\
\text { RNAi } \\
\text { Designer }\end{array}$ & $\begin{array}{l}\text { Thermo } \\
\text { Fisher } \\
\text { Scientific }\end{array}$ & $\begin{array}{l}\text { RRID:SCR_00 } \\
2794\end{array}$ & $\begin{array}{l}\text { https://rnaidesi } \\
\text { gner.thermofis } \\
\text { her.com/rnaiex } \\
\text { press/ }\end{array}$ \\
\hline $\begin{array}{l}\text { Software, } \\
\text { algorithm }\end{array}$ & Prism & GraphPad & $\begin{array}{l}\text { RRID:SCR_00 } \\
2798\end{array}$ & \\
\hline $\begin{array}{l}\text { Software, } \\
\text { algorithm }\end{array}$ & $\begin{array}{l}\text { Traction } \\
\text { Force plugin }\end{array}$ & (94) & & \\
\hline
\end{tabular}




\section{References}

1. Forthal DN, Functions of Antibodies. Microbiol. Spectr. 2, 1-17 (2014).

2. Heesters BA, van der Poel CE, Das A, \& Carroll MC, Antigen Presentation to B Cells. Trends in Immunology 37, 844-854 (2016). 10.1016/j.it.2016.10.003.

3. Harwood NE \& Batista FD, The cytoskeleton coordinates the early events of B-cell activation. Cold Spring Harb. Perspect. Biol. 3, a002360 (2011). 10.1101/cshperspect.a002360.

4. Gonzalez SF, et al., Trafficking of B cell antigen in lymph nodes. Annu. Rev. Immunol. 29, 215-233 (2011). 10.1146/annurev-immunol-031210-101255.

5. Carrasco YR \& Batista FD, B cell recognition of membrane-bound antigen: an exquisite way of sensing ligands. Curr. Opin. Immunol. 18, 286-291 (2006). 10.1016/j.coi.2006.03.013.

6. Cyster JG, B cell follicles and antigen encounters of the third kind. Nat. Immunol. 11, 989-996 (2010). 10.1038/ni.1946.

7. Wang JC \& Hammer JA, The role of actin and myosin in antigen extraction by B lymphocytes. Semin. Cell Dev. Biol. 102, 90-104 (2020). 10.1016/j.semcdb.2019.10.017.

8. Song W, Liu C, \& Upadhyaya A, The pivotal position of the actin cytoskeleton in the initiation and regulation of B cell receptor activation. Biochim. Biophys. Acta 1838, 569-578 (2014). 10.1016/j.bbamem.2013.07.016.

9. Fleire SJ, et al., B cell ligand discrimination through a spreading and contraction response. Science 312, 738-741 (2006). 10.1126/science.1123940.

10. Tolar P, Sohn HW, Liu W, \& Pierce SK, The molecular assembly and organization of signaling active B-cell receptor oligomers. Immunol. Rev. 232, 34-41 (2009). 10.1111/j.1600065X.2009.00833.x.

11. Mattila PK, Batista FD, \& Treanor B, Dynamics of the actin cytoskeleton mediates receptor cross talk: An emerging concept in tuning receptor signaling. J. Cell Biol. 212, 267-280 (2016). 10.1083/jcb.201504137.

12. Treanor B, Harwood NE, \& Batista FD, Microsignalosomes: spatially resolved receptor signalling. Biochem. Soc. Trans. 37, 1014-1018 (2009). 10.1042/BST0371014.

13. Bolger-Munro $M$, et al., Arp2/3 complex-driven spatial patterning of the BCR enhances immune synapse formation, BCR signaling and cell activation. Elife 8, (2019). 10.7554/eLife.44574.

14. Batista FD, Treanor B, \& Harwood NE, Visualizing a role for the actin cytoskeleton in the regulation of B-cell activation. Immunol. Rev. 237, 191-204 (2010). 10.1111/j.1600065X.2010.00943.x.

15. Batista FD, Iber D, \& Neuberger MS, B cells acquire antigen from target cells after synapse formation. Nature 411, 489-494 (2001). 10.1038/35078099.

16. Yuseff MI, Pierobon P, Reversat A, \& Lennon-Dumenil AM, How B cells capture, process and present antigens: a crucial role for cell polarity. Nat. Rev. Immunol. 13, 475-486 (2013). 10.1038/nri3469.

17. Yuseff MI \& Lennon-Dumenil AM, B cells use conserved polarity cues to regulate their antigen processing and presentation functions. Front. Immunol. 6, 251 (2015). 10.3389/fimmu.2015.00251.

18. Carrasco YR, Fleire SJ, Cameron T, Dustin ML, \& Batista FD, LFA-1/ICAM-1 interaction lowers the threshold of $B$ cell activation by facilitating $B$ cell adhesion and synapse formation. Immunity 20 , 589-599 (2004).

19. Carrasco YR \& Batista FD, B-cell activation by membrane-bound antigens is facilitated by the interaction of VLA-4 with VCAM-1. EMBO J. 25, 889-899 (2006). 10.1038/sj.emboj.7600944. 
20. Springer TA, Adhesion receptors of the immune system. Nature 346, 425-434 (1990). 10.1038/346425a0.

21. Springer TA, Dustin ML, Kishimoto TK, \& Marlin SD, The lymphocyte function-associated LFA-1, CD2, and LFA-3 molecules: cell adhesion receptors of the immune system. Annu. Rev. Immunol. 5, 223-252 (1987). 10.1146/annurev.iy.05.040187.001255.

22. Wang JC, Bolger-Munro M, \& Gold MR, Visualizing the Actin and Microtubule Cytoskeletons at the B-cell Immune Synapse Using Stimulated Emission Depletion (STED) Microscopy. J. Vis. Exp. (2018). 10.3791/57028.

23. Freeman SA, et al., Cofilin-mediated F-actin severing is regulated by the Rap GTPase and controls the cytoskeletal dynamics that drive lymphocyte spreading and BCR microcluster formation. J. Immunol. 187, 5887-5900 (2011). 10.4049/jimmunol.1102233.

24. Liu C, et al., Actin reorganization is required for the formation of polarized B cell receptor signalosomes in response to both soluble and membrane-associated antigens. J. Immunol. 188, 3237-3246 (2012). 10.4049/jimmunol.1103065.

25. Wang JC, et al., The Rap1-cofilin-1 pathway coordinates actin reorganization and MTOC polarization at the B cell immune synapse. J. Cell Sci. 130, 1094-1109 (2017). 10.1242/jcs.191858.

26. Yi J, Wu XS, Crites T, \& Hammer JA, 3rd, Actin retrograde flow and actomyosin II arc contraction drive receptor cluster dynamics at the immunological synapse in Jurkat T cells. Mol. Biol. Cell 23, 834-852 (2012). 10.1091/mbc.E11-08-0731.

27. Murugesan $\mathrm{S}$, et al., Formin-generated actomyosin arcs propel T cell receptor microcluster movement at the immune synapse. J. Cell Biol. 215, 383-399 (2016). 10.1083/jcb.201603080.

28. Fritzsche $\mathrm{M}$, et al., Self-organizing actin patterns shape membrane architecture but not cell mechanics. Nature communications 8, 14347 (2017). 10.1038/ncomms14347.

29. Boudaoud A, et al., FibrilTool, an ImageJ plug-in to quantify fibrillar structures in raw microscopy images. Nat. Protoc. 9, 457-463 (2014). 10.1038/nprot.2014.024.

30. Goode BL \& Eck MJ, Mechanism and function of formins in the control of actin assembly. Annu. Rev. Biochem. 76, 593-627 (2007). 10.1146/annurev.biochem.75.103004.142647.

31. Breitsprecher D \& Goode BL, Formins at a glance. J. Cell Sci. 126, 1-7 (2013). 10.1242/jcs.107250.

32. Chen $Q, N a g ~ S, \&$ Pollard TD, Formins filter modified actin subunits during processive elongation. J. Struct. Biol. 177, 32-39 (2012). 10.1016/j.jsb.2011.10.005.

33. Rizvi SA, et al., Identification and characterization of a small molecule inhibitor of forminmediated actin assembly. Chem. Biol. 16, 1158-1168 (2009). 10.1016/j.chembiol.2009.10.006.

34. Nishimura Y, et al., The formin inhibitor SMIFH2 inhibits members of the myosin superfamily. $J$. Cell Sci. 134, (2021). 10.1242/jcs.253708.

35. Burke TA, et al., Homeostatic actin cytoskeleton networks are regulated by assembly factor competition for monomers. Curr. Biol. 24, 579-585 (2014). 10.1016/j.cub.2014.01.072.

36. Lomakin AJ, et al., Competition for actin between two distinct F-actin networks defines a bistable switch for cell polarization. Nat. Cell Biol. 17, 1435-1445 (2015). 10.1038/ncb3246.

37. Fritzsche M, Erlenkamper C, Moeendarbary E, Charras G, \& Kruse K, Actin kinetics shapes cortical network structure and mechanics. Sci. Adv. 2, e1501337 (2016). 10.1126/sciadv.1501337.

38. Hammer JA, Wang JC, Saeed M, \& Pedrosa AT, Origin, Organization, Dynamics, and Function of Actin and Actomyosin Networks at the T Cell Immunological Synapse. Annu. Rev. Immunol. 37, 201-224 (2019). 10.1146/annurev-immunol-042718-041341.

39. Vicente-Manzanares M, Ma X, Adelstein RS, \& Horwitz AR, Non-muscle myosin II takes centre stage in cell adhesion and migration. Nat. Rev. Mol. Cell Biol. 10, 778-790 (2009). $10.1038 / \mathrm{nrm} 2786$. 
40. Sellers JR, Myosins: a diverse superfamily. Biochim. Biophys. Acta 1496, 3-22 (2000). 10.1016/s0167-4889(00)00005-7.

41. Shutova MS \& Svitkina TM, Common and Specific Functions of Nonmuscle Myosin II Paralogs in Cells. Biochemistry (Mosc) 83, 1459-1468 (2018). 10.1134/S0006297918120040.

42. Zhang Y, et al., Mouse models of MYH9-related disease: mutations in nonmuscle myosin II-A. Blood 119, 238-250 (2012). 10.1182/blood-2011-06-358853.

43. Beach JR, et al., Nonmuscle myosin II isoforms coassemble in living cells. Curr. Biol. 24, 11601166 (2014). 10.1016/j.cub.2014.03.071.

44. Beach JR, et al., Actin dynamics and competition for myosin monomer govern the sequential amplification of myosin filaments. Nat. Cell Biol. 19, 85-93 (2017). 10.1038/ncb3463.

45. Beach JR \& Hammer JA, 3rd, Myosin II isoform co-assembly and differential regulation in mammalian systems. Exp. Cell Res. 334, 2-9 (2015). 10.1016/j.yexcr.2015.01.012.

46. Kepiro M, et al., para-Nitroblebbistatin, the non-cytotoxic and photostable myosin II inhibitor. Angew. Chem. Int. Ed. Engl. 53, 8211-8215 (2014). 10.1002/anie.201403540.

47. Wang J, et al., Profiling the origin, dynamics, and function of traction force in B cell activation. Sci. Signal. 11, (2018). 10.1126/scisignal.aai9192.

48. Kumari A, et al., Actomyosin-driven force patterning controls endocytosis at the immune synapse. Nat. Commun. 10, 2870 (2019). 10.1038/s41467-019-10751-7.

49. Gardel ML, Schneider IC, Aratyn-Schaus Y, \& Waterman CM, Mechanical integration of actin and adhesion dynamics in cell migration. Annu. Rev. Cell. Dev. Biol. 26, 315-333 (2010). 10.1146/annurev.cellbio.011209.122036.

50. Case LB \& Waterman CM, Integration of actin dynamics and cell adhesion by a threedimensional, mechanosensitive molecular clutch. Nat. Cell Biol. 17, 955-963 (2015). 10.1038/ncb3191.

51. Comrie WA \& Burkhardt JK, Action and Traction: Cytoskeletal Control of Receptor Triggering at the Immunological Synapse. Front. Immunol. 7, 68 (2016). 10.3389/fimmu.2016.00068.

52. Blumenthal D \& Burkhardt JK, Multiple actin networks coordinate mechanotransduction at the immunological synapse. J Cell Biol 219, (2020). 10.1083/jcb.201911058.

53. Schnyder $\mathrm{T}$, et al., B cell receptor-mediated antigen gathering requires ubiquitin ligase $\mathrm{Cbl}$ and adaptors Grb2 and Dok-3 to recruit dynein to the signaling microcluster. Immunity 34, 905-918 (2011). 10.1016/j.immuni.2011.06.001.

54. Babich A \& Burkhardt JK, Lymphocyte signaling converges on microtubules. Immunity 34, 825827 (2011). 10.1016/j.immuni.2011.06.004.

55. Yu CH, Wu HJ, Kaizuka Y, Vale RD, \& Groves JT, Altered actin centripetal retrograde flow in physically restricted immunological synapses. PLoS One 5, e11878 (2010).

10.1371/journal.pone.0011878.

56. Ditlev JA, et al., A composition-dependent molecular clutch between $\mathrm{T}$ cell signaling condensates and actin. Elife 8, (2019). 10.7554/eLife.42695.

57. Smoligovets AA, Smith AW, Wu HJ, Petit RS, \& Groves JT, Characterization of dynamic actin associations with T-cell receptor microclusters in primary T cells. J. Cell Sci. 125, 735-742 (2012). $10.1242 /$ jcs.092825.

58. Varkuti BH, et al., A highly soluble, non-phototoxic, non-fluorescent blebbistatin derivative. Sci. Rep. 6, 26141 (2016). 10.1038/srep26141.

59. Tanaka S \& Baba Y, B Cell Receptor Signaling. Adv. Exp. Med. Biol. 1254, 23-36 (2020). 10.1007/978-981-15-3532-1_2.

60. Tuveson DA, Carter RH, Soltoff SP, \& Fearon DT, CD19 of B cells as a surrogate kinase insert region to bind phosphatidylinositol 3-kinase. Science 260, 986-989 (1993).

10.1126/science.7684160. 
61. Keppler SJ, et al., Wiskott-Aldrich Syndrome Interacting Protein Deficiency Uncovers the Role of the Co-receptor CD19 as a Generic Hub for PI3 Kinase Signaling in B Cells. Immunity 43, 660-673 (2015). 10.1016/j.immuni.2015.09.004.

62. Depoil D, et al., CD19 is essential for B cell activation by promoting B cell receptor-antigen microcluster formation in response to membrane-bound ligand. Nat. Immunol. 9, 63-72 (2008). 10.1038/ni1547.

63. Nowosad CR, Spillane KM, \& Tolar P, Germinal center B cells recognize antigen through a specialized immune synapse architecture. Nat. Immunol. 17, 870-877 (2016). 10.1038/ni.3458.

64. Kwak K, et al., Intrinsic properties of human germinal center B cells set antigen affinity thresholds. Sci. Immunol. 3, (2018). 10.1126/sciimmunol.aau6598.

65. Kuhn S \& Geyer M, Formins as effector proteins of Rho GTPases. Small GTPases 5, e29513 (2014). 10.4161/sgtp.29513.

66. Rose $\mathrm{R}$, et al., Structural and mechanistic insights into the interaction between Rho and mammalian Dia. Nature 435, 513-518 (2005). 10.1038/nature03604.

67. Nezami AG, Poy F, \& Eck MJ, Structure of the autoinhibitory switch in formin mDia1. Structure 14, 257-263 (2006). 10.1016/j.str.2005.12.003.

68. Maiti S, et al., Structure and activity of full-length formin mDia1. Cytoskeleton (Hoboken, N.J.) 69, 393-405 (2012). 10.1002/cm.21033.

69. Staus DP, Taylor JM, \& Mack CP, Enhancement of mDia2 activity by Rho-kinase-dependent phosphorylation of the diaphanous autoregulatory domain. Biochem. J. 439, 57-65 (2011). 10.1042/BJ20101700.

70. Guilluy $\mathrm{C}$, et al., The Rho GEFs LARG and GEF-H1 regulate the mechanical response to force on integrins. Nat. Cell Biol. 13, 722-727 (2011). 10.1038/ncb2254.

71. Lawson $C D$ \& Burridge $K$, The on-off relationship of Rho and Rac during integrin-mediated adhesion and cell migration. Small GTPases 5, e27958 (2014). 10.4161/sgtp. 27958.

72. Saci A \& Carpenter CL, RhoA GTPase regulates B cell receptor signaling. Mol. Cell 17, 205-214 (2005). 10.1016/j.molcel.2004.12.012.

73. Saez de Guinoa J, Barrio L, Mellado M, \& Carrasco YR, CXCL13/CXCR5 signaling enhances BCRtriggered B-cell activation by shaping cell dynamics. Blood 118, 1560-1569 (2011). 10.1182/blood-2011-01-332106.

74. Merino-Cortes SV, et al., Diacylglycerol kinase zeta promotes actin cytoskeleton remodeling and mechanical forces at the B cell immune synapse. Sci. Signal. 13, (2020).

10.1126/scisignal.aaw8214.

75. Dustin ML, Chakraborty AK, \& Shaw AS, Understanding the structure and function of the immunological synapse. Cold Spring Harb. Perspect. Biol. 2, a002311 (2010).

10.1101/cshperspect.a002311.

76. Nordenfelt P, Elliott HL, \& Springer TA, Coordinated integrin activation by actin-dependent force during T-cell migration. Nat. Commun. 7, 13119 (2016). 10.1038/ncomms13119.

77. Parsons JT, Horwitz AR, \& Schwartz MA, Cell adhesion: integrating cytoskeletal dynamics and cellular tension. Nat. Rev. Mol. Cell Biol. 11, 633-643 (2010). 10.1038/nrm2957.

78. Comrie WA, Li S, Boyle S, \& Burkhardt JK, The dendritic cell cytoskeleton promotes T cell adhesion and activation by constraining ICAM-1 mobility. J. Cell Biol. 208, 457-473 (2015). 10.1083/jcb.201406120.

79. Tee $\mathrm{YH}$, et al., Cellular chirality arising from the self-organization of the actin cytoskeleton. Nature cell biology 17, 445-457 (2015). 10.1038/ncb3137.

80. Tojkander S, Gateva G, Husain A, Krishnan R, \& Lappalainen P, Generation of contractile actomyosin bundles depends on mechanosensitive actin filament assembly and disassembly. Elife 4, e06126 (2015). 10.7554/eLife.06126. 
81. Burnette DT, et al., A contractile and counterbalancing adhesion system controls the 3D shape of crawling cells. J Cell Biol 205, 83-96 (2014). 10.1083/jcb.201311104.

82. Heesters BA, Myers RC, \& Carroll MC, Follicular dendritic cells: dynamic antigen libraries. Nature reviews. Immunology 14, 495-504 (2014). 10.1038/nri3689.

83. Basu R, et al., Cytotoxic T Cells Use Mechanical Force to Potentiate Target Cell Killing. Cell 165, 100-110 (2016). 10.1016/j.cell.2016.01.021.

84. Natkanski E, et al., B cells use mechanical energy to discriminate antigen affinities. Science 340, 1587-1590 (2013). 10.1126/science.1237572.

85. Hoogeboom R, et al., Myosin Ila Promotes Antibody Responses by Regulating B Cell Activation, Acquisition of Antigen, and Proliferation. Cell Rep. 23, 2342-2353 (2018). 10.1016/j.celrep.2018.04.087.

86. Spillane KM \& Tolar P, Mechanics of antigen extraction in the B cell synapse. Mol. Immunol. 101, 319-328 (2018). 10.1016/j.molimm.2018.07.018.

87. Roper SI, et al., B cells extract antigens at Arp2/3-generated actin foci interspersed with linear filaments. Elife 8, (2019). 10.7554/eLife.48093.

88. Hwang IY, et al., An essential role for RGS protein/Galphai2 interactions in B lymphocytedirected cell migration and trafficking. J. Immunol. 194, 2128-2139 (2015). 10.4049/jimmunol.1401952.

89. Alexander CJ \& Hammer JA, 3rd, Optimization of cerebellar purkinje neuron cultures and development of a plasmid-based method for purkinje neuron-specific, miRNA-mediated protein knockdown. Methods Cell Biol. 131, 177-197 (2016). 10.1016/bs.mcb.2015.06.004.

90. Cai D, Latham VM, Jr., Zhang X, \& Shapiro GI, Combined depletion of cell cycle and transcriptional cyclin-dependent kinase activities induces apoptosis in cancer cells. Cancer Res 66, 9270-9280 (2006). 10.1158/0008-5472.CAN-06-1758.

91. Hong J, Murugesan S, Betzig E, \& Hammer JA, Contractile actomyosin arcs promote the activation of primary mouse T cells in a ligand-dependent manner. PLoS One 12, e0183174 (2017). 10.1371/journal.pone.0183174.

92. Comrie WA, Babich A, \& Burkhardt JK, F-actin flow drives affinity maturation and spatial organization of LFA-1 at the immunological synapse. J. Cell Biol. 208, 475-491 (2015). 10.1083/jcb.201406121.

93. Jaumouille V, Cartagena-Rivera AX, \& Waterman CM, Coupling of beta2 integrins to actin by a mechanosensitive molecular clutch drives complement receptor-mediated phagocytosis. Nat. Cell Biol. 21, 1357-1369 (2019). 10.1038/s41556-019-0414-2.

94. Martiel JL, et al., Measurement of cell traction forces with ImageJ. Methods Cell Biol. 125, 269287 (2015). 10.1016/bs.mcb.2014.10.008.

95. Burgess $A$, et al., Loss of human Greatwall results in $\mathrm{G} 2$ arrest and multiple mitotic defects due to deregulation of the cyclin B-Cdc2/PP2A balance. Proc. Natl. Acad. Sci. 107, 12564-12569 (2010). 10.1073/pnas.0914191107.

96. Tinevez JY, et al., TrackMate: An open and extensible platform for single-particle tracking. Methods 115, 80-90 (2017). 10.1016/j.ymeth.2016.09.016.

97. Schindelin J, et al., Fiji: an open-source platform for biological-image analysis. Nat Methods $\mathbf{9}$, 676-682 (2012). 10.1038/nmeth.2019. 
bioRxiv preprint doi: https://doi.org/10.1101/2021.08.12.456133; this version posted February 10, 2022. The copyright holder for this preprint (which was not certified by peer review) is the author/funder. This article is a US Government work. It is not subject to copyright under 17 USC Figure 1 - figure supplement 1105 and is also made available for use under a CC0 license.
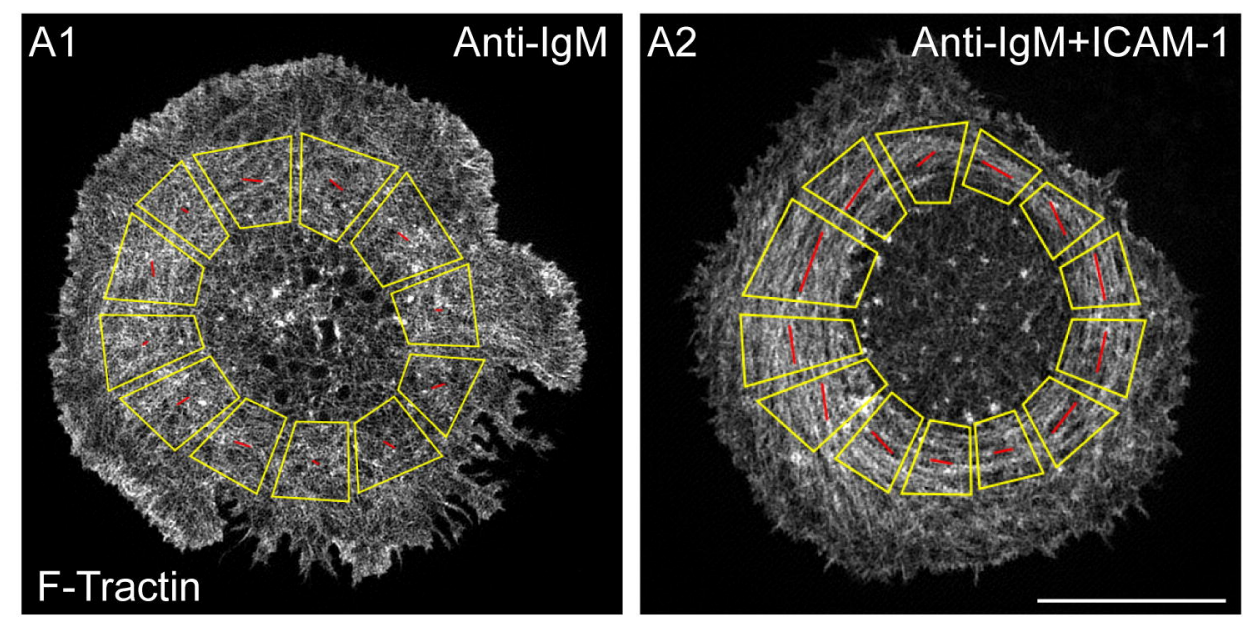

A3

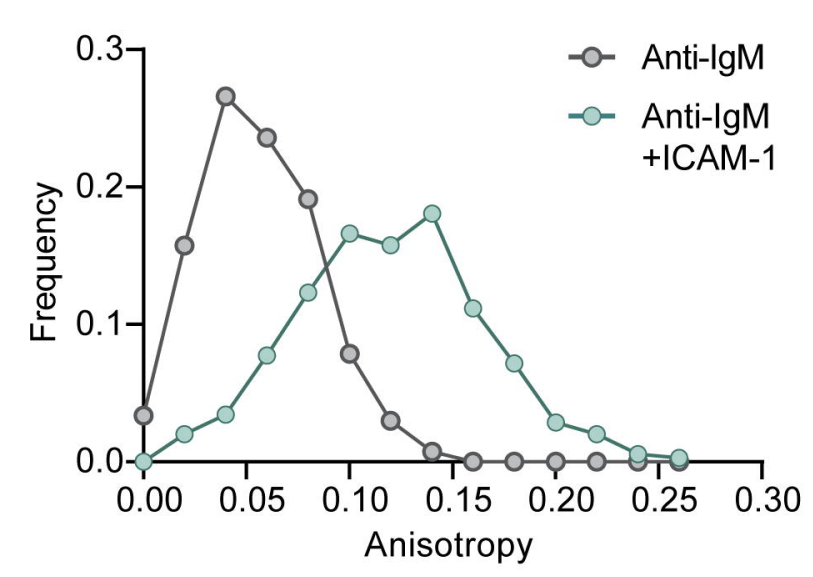




\section{Figure 2}

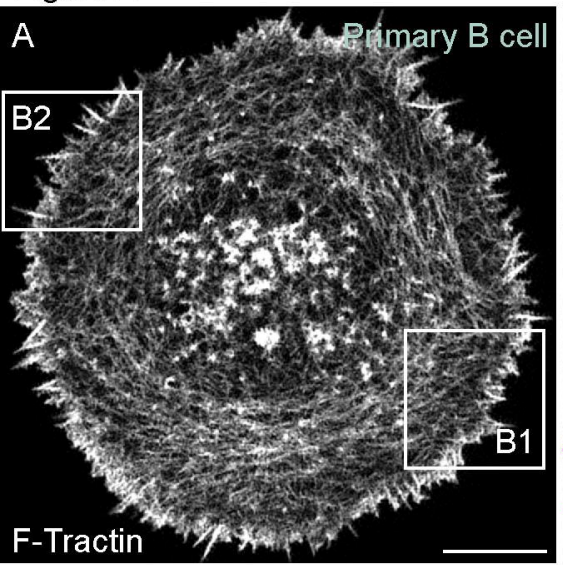

\section{Vector}

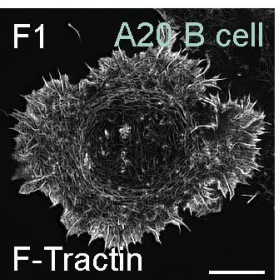

miRNA\#1

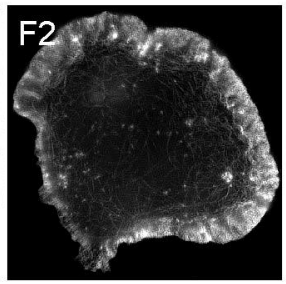

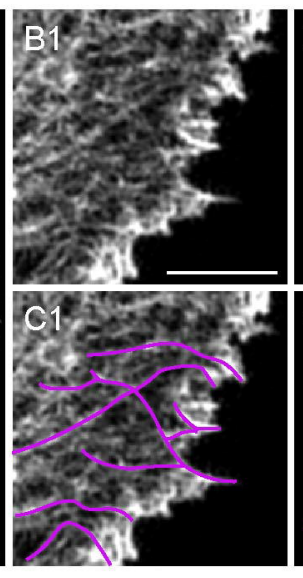

miRNA\#2

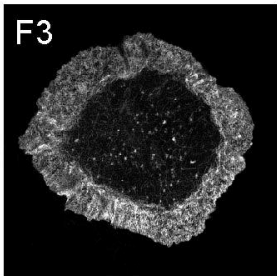

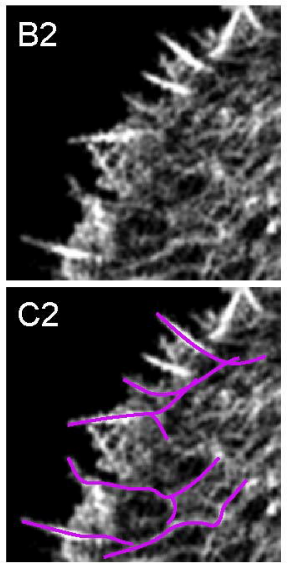

miRNA\#3

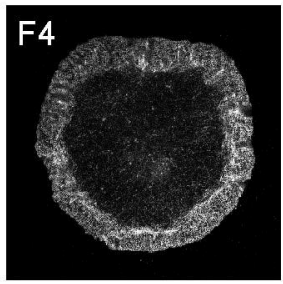

$\mathrm{H}$
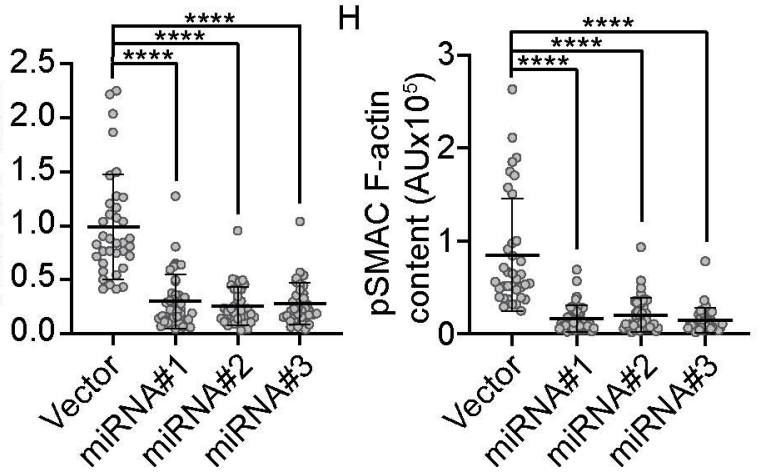

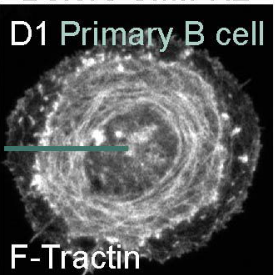

E
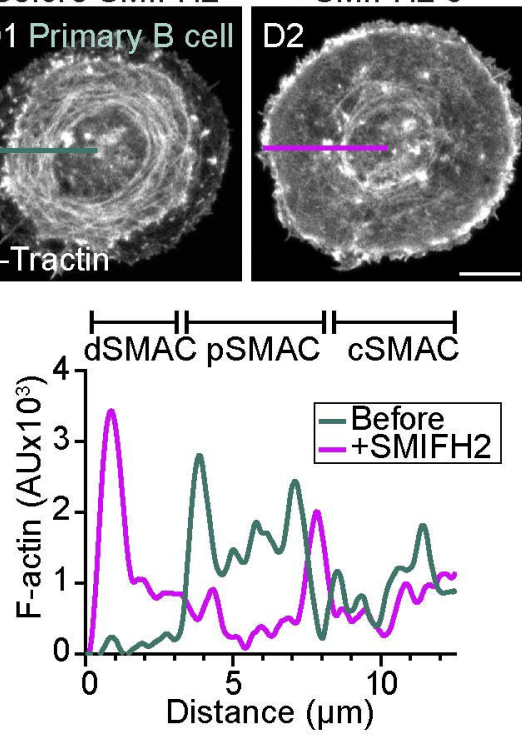

G

.

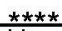

+SMIFH2 6'

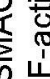

\%

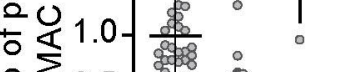

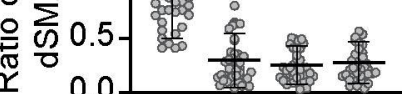

$-12$ 


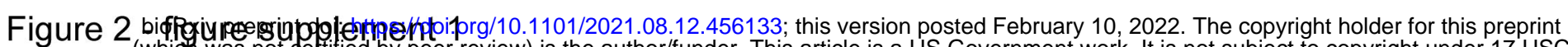
A 105 and is also made available for use under a CCO license.

B
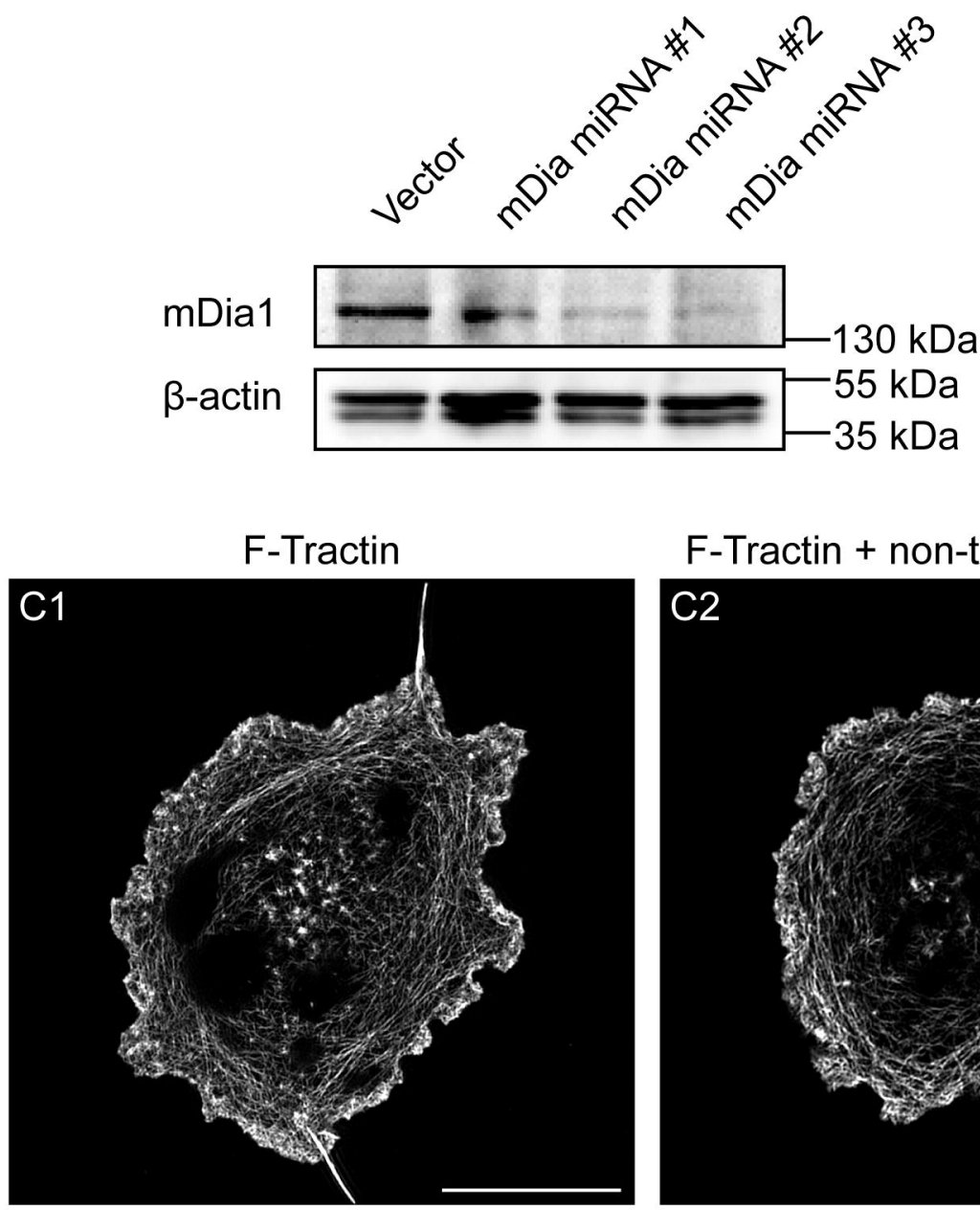

F-Tractin + non-targeting miRNA

C3

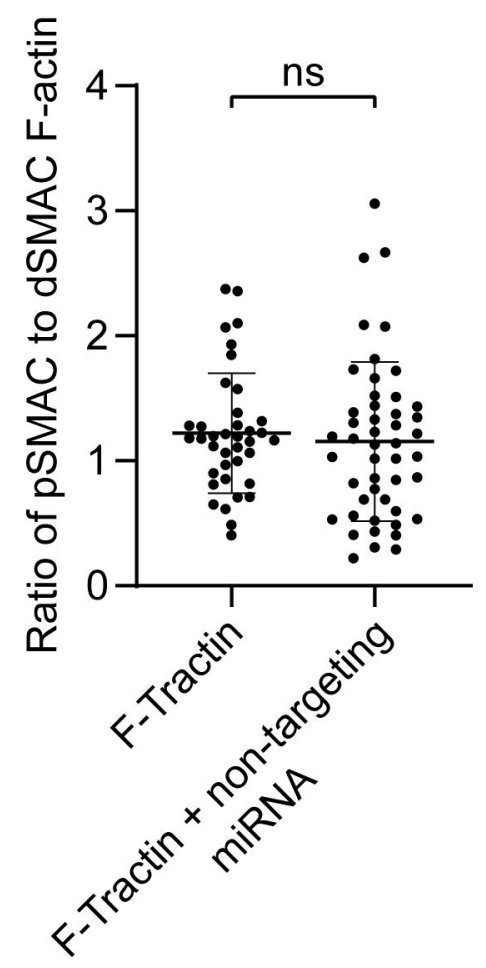

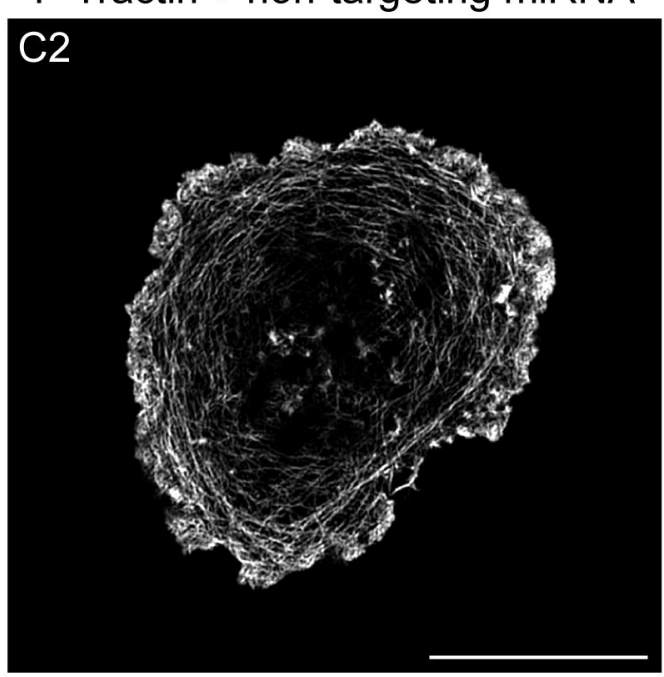

C4

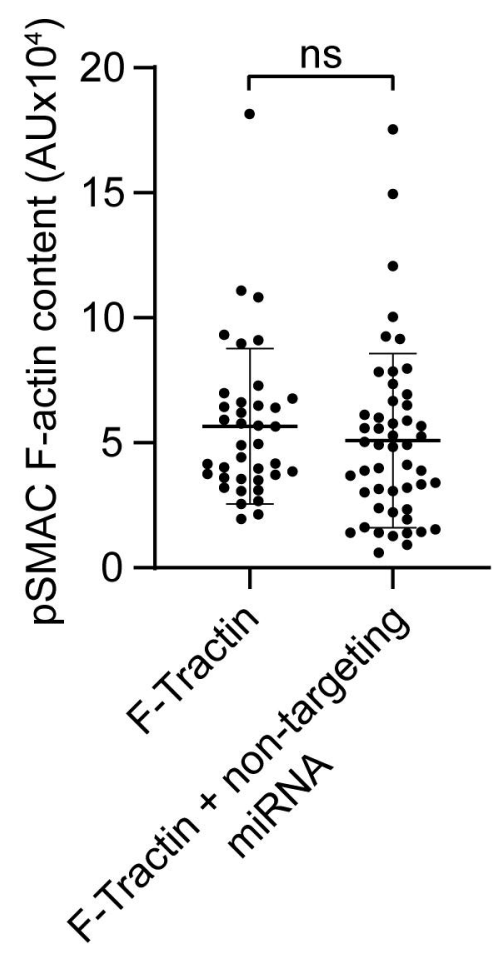




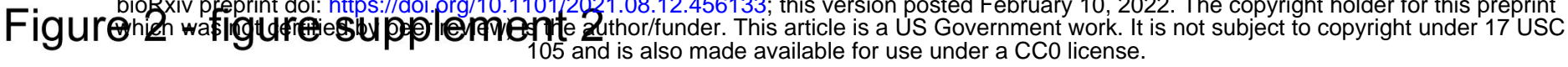

Before CK-666

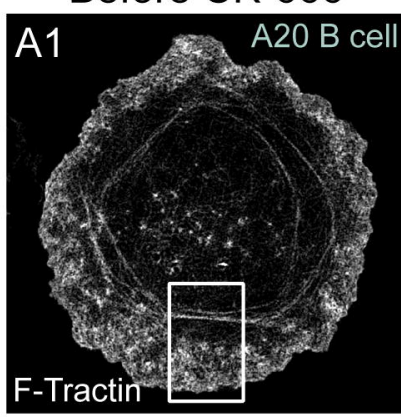

C

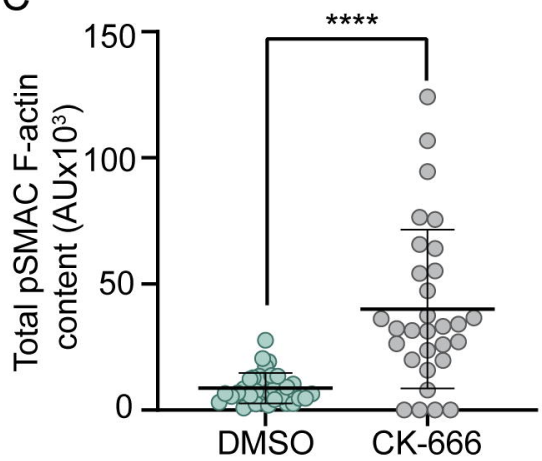

After CK-666

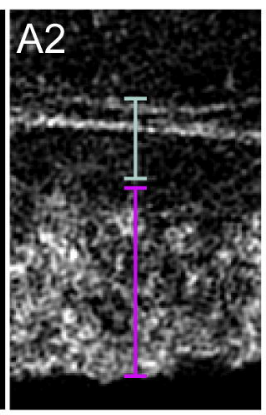

$\mathrm{D}$

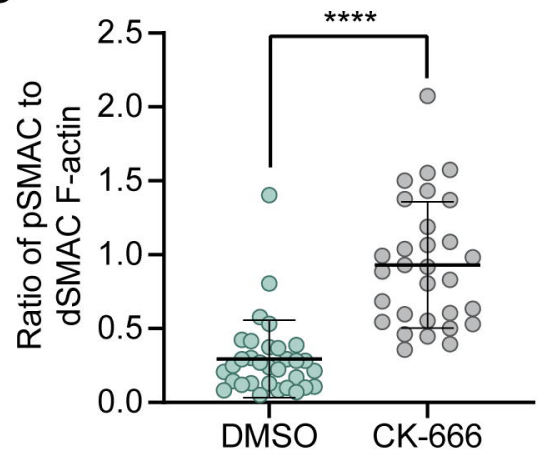

$B$

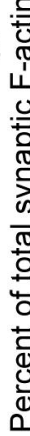

\begin{tabular}{ll|}
\hline - DMSO \\
- & CK-666 \\
\hline
\end{tabular}

$\mathrm{E}$

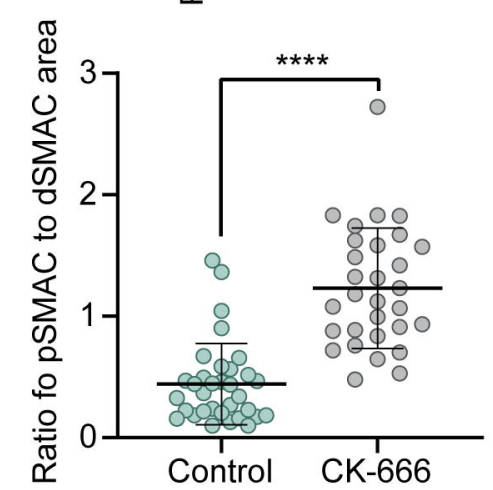




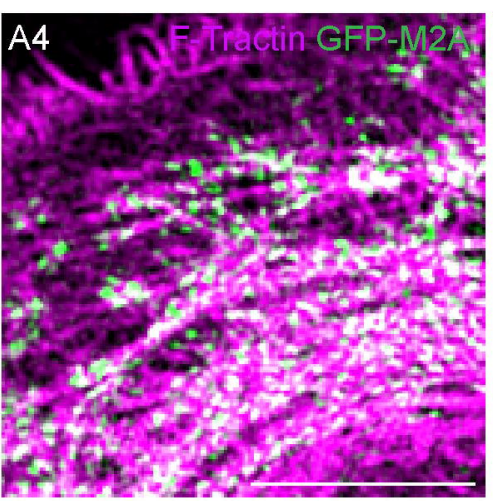

C

\section{Phalloidin GFP-M2A}

F

\section{Anti-igM}

D

GFP-M2A
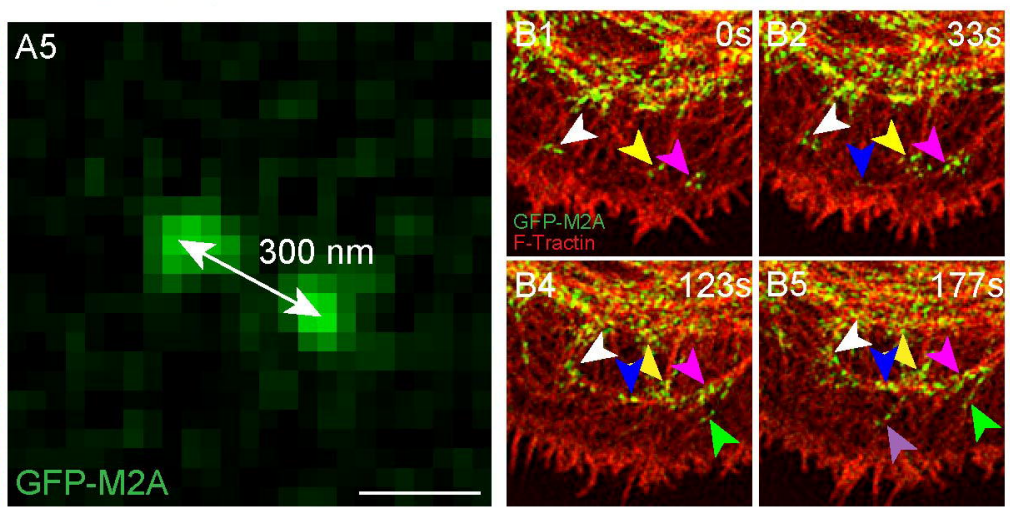

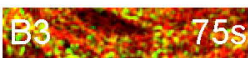

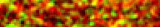

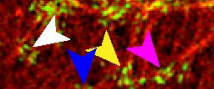
in 255 s
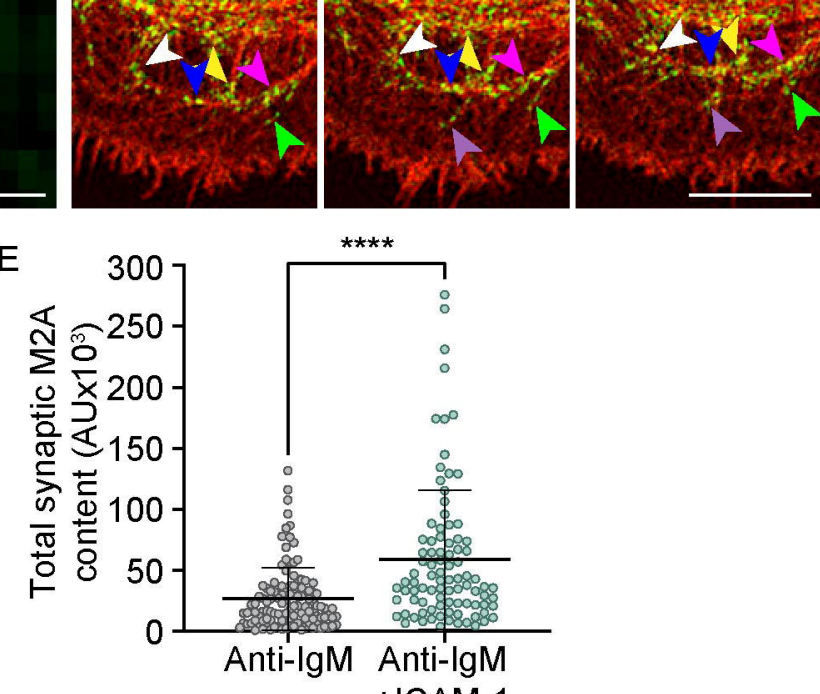

$\mathrm{H}$

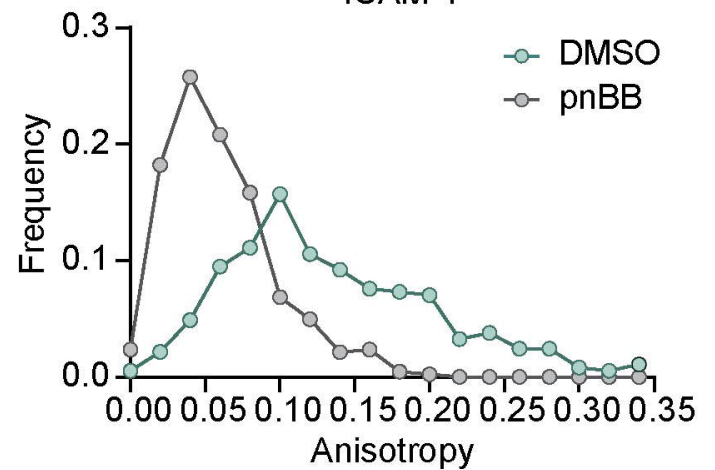


Figure 3 - figure supplement 2

DIC

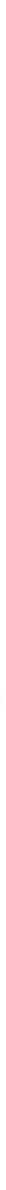

Force magnitude $(\mathrm{Pa})$

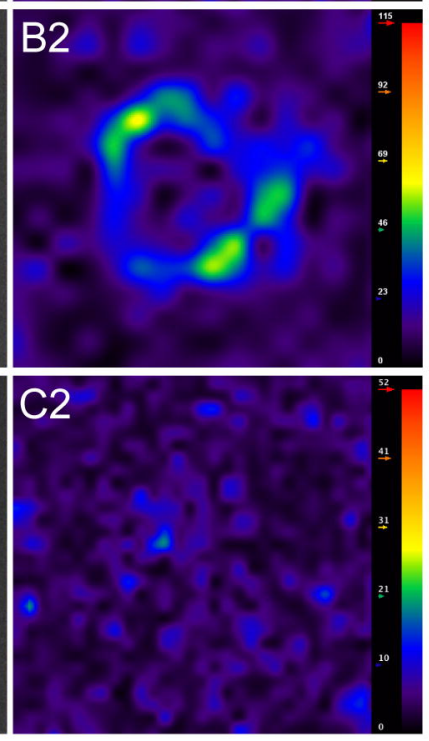

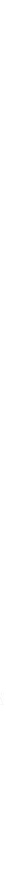

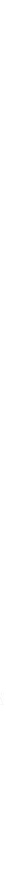



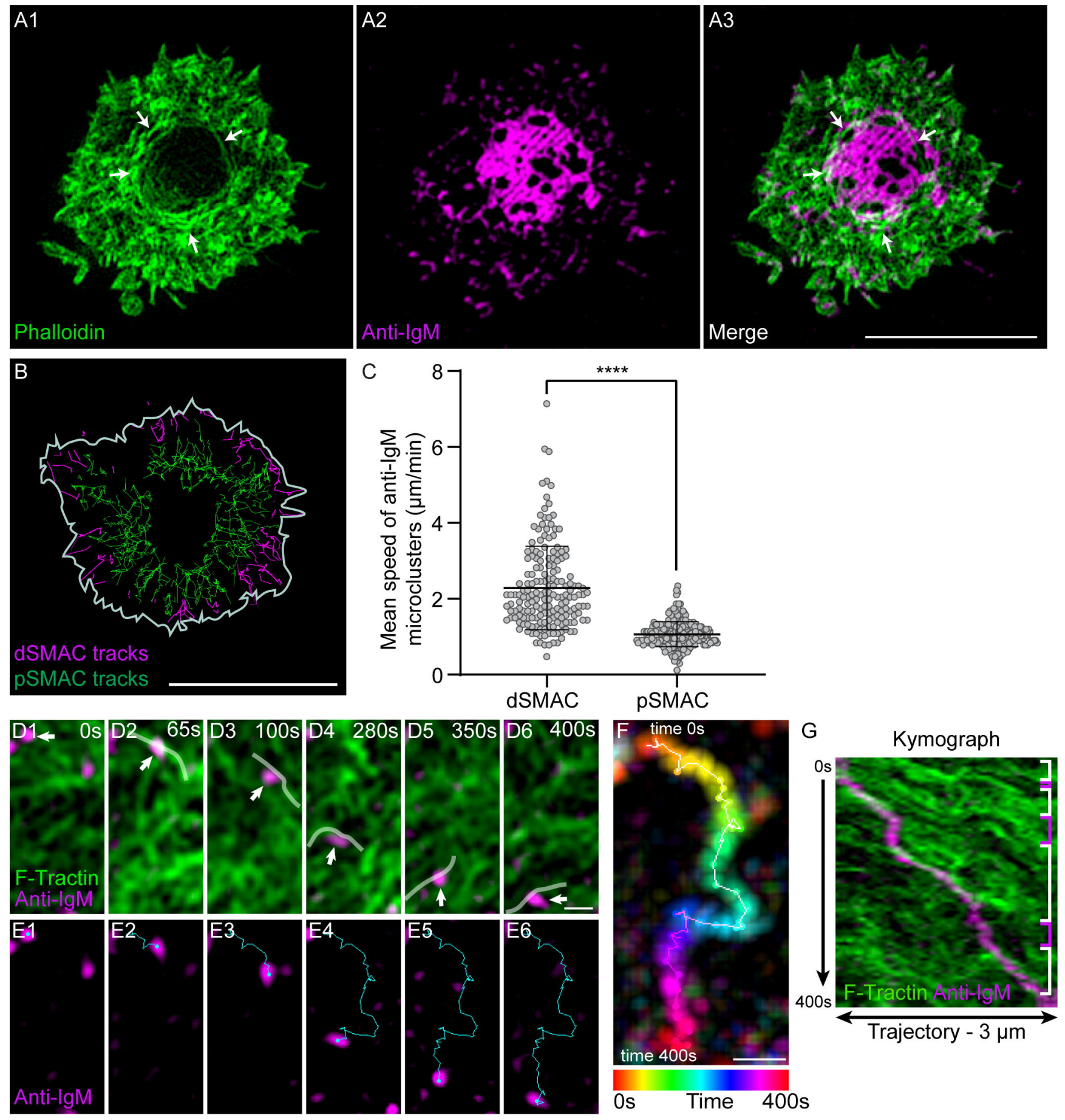

105 and is also made available for use under a CCO license.

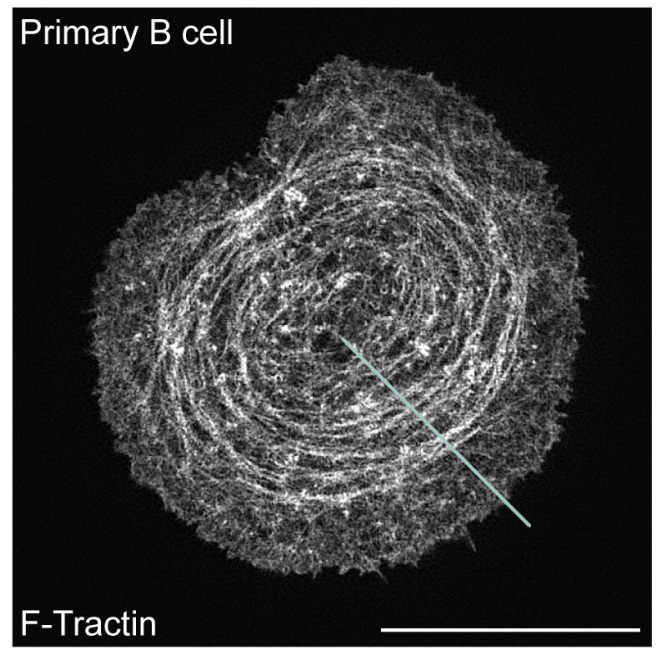

B1

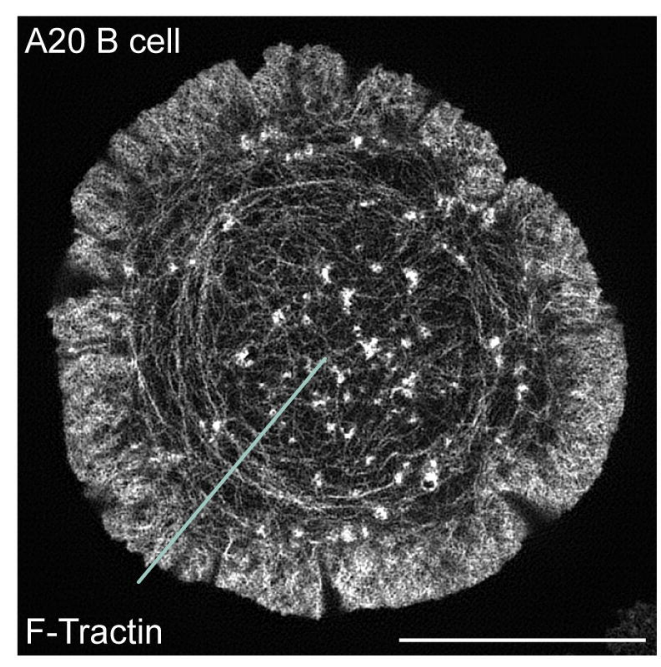

A2

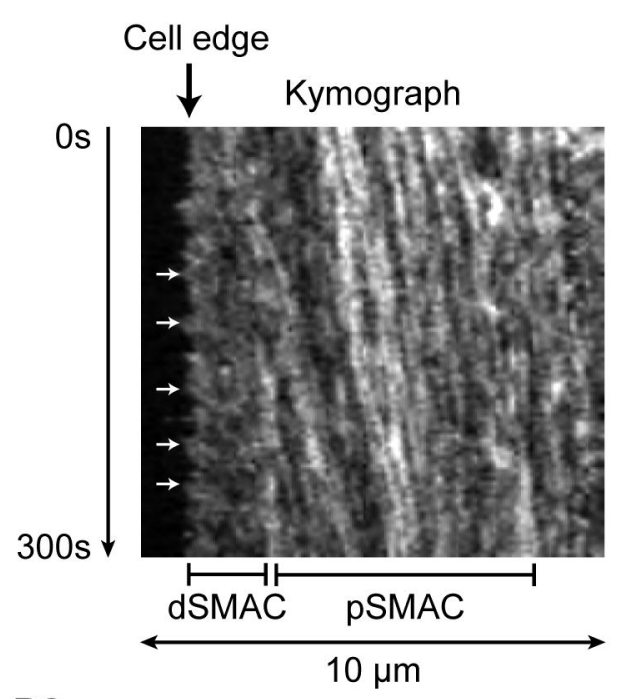

B2

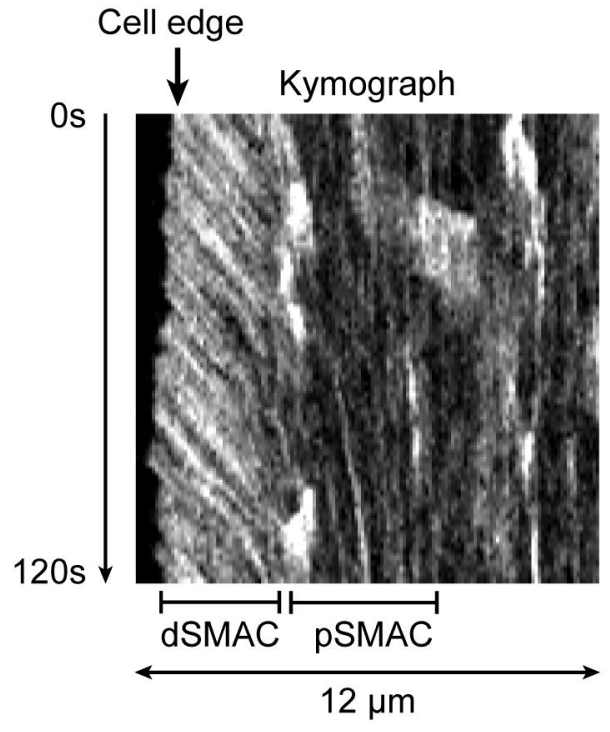

A3

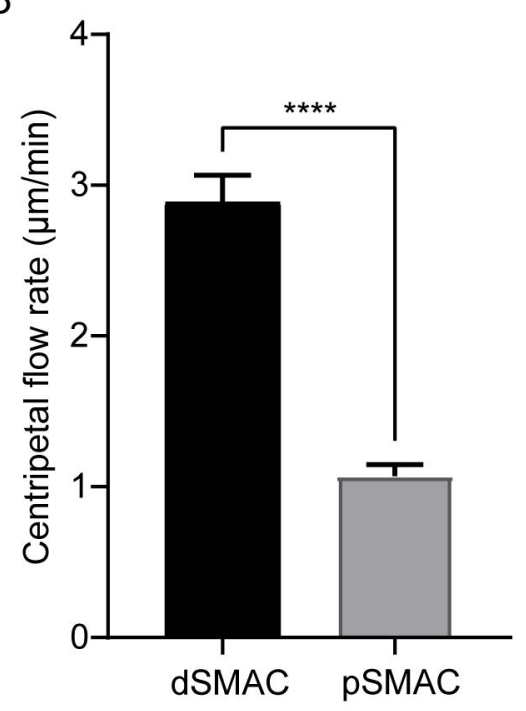

B3

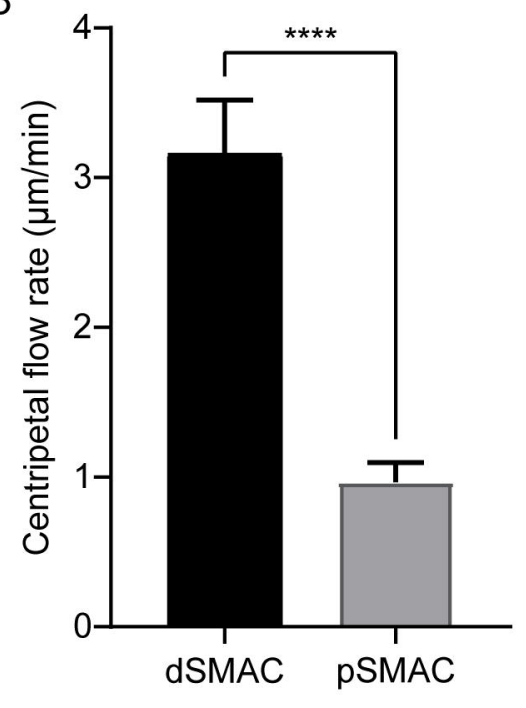



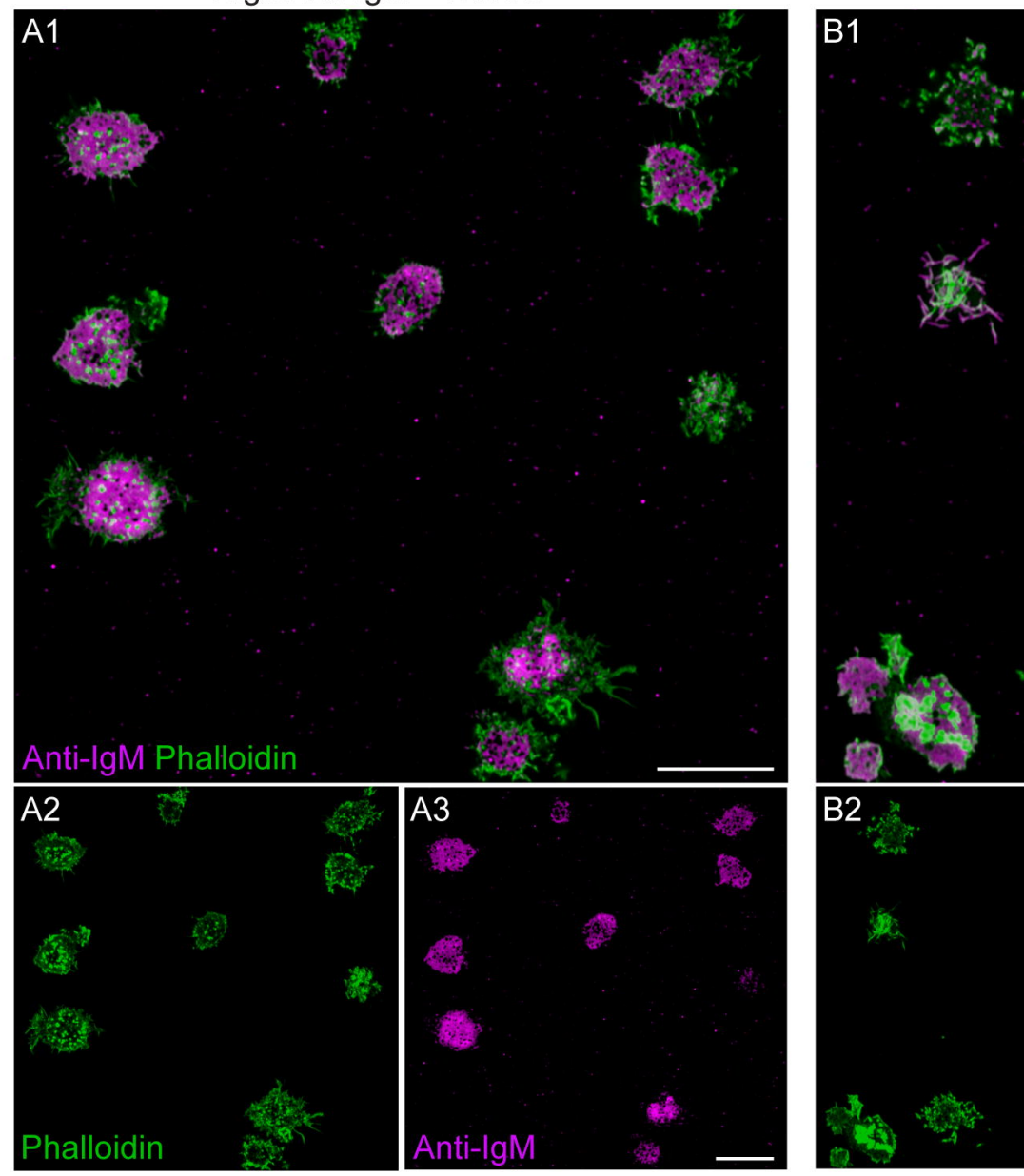

High Anti-lgM + paBB

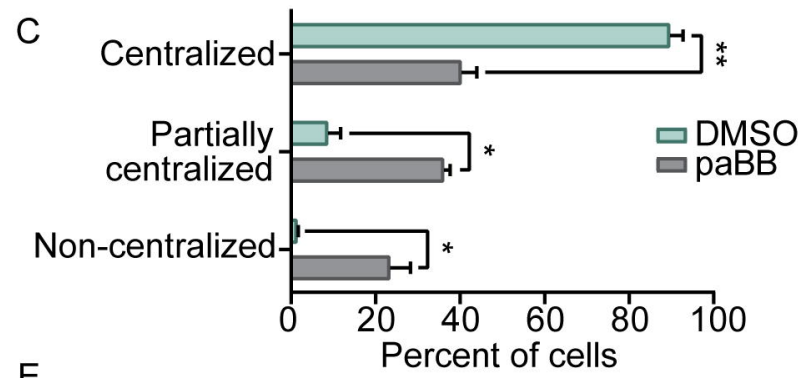

E
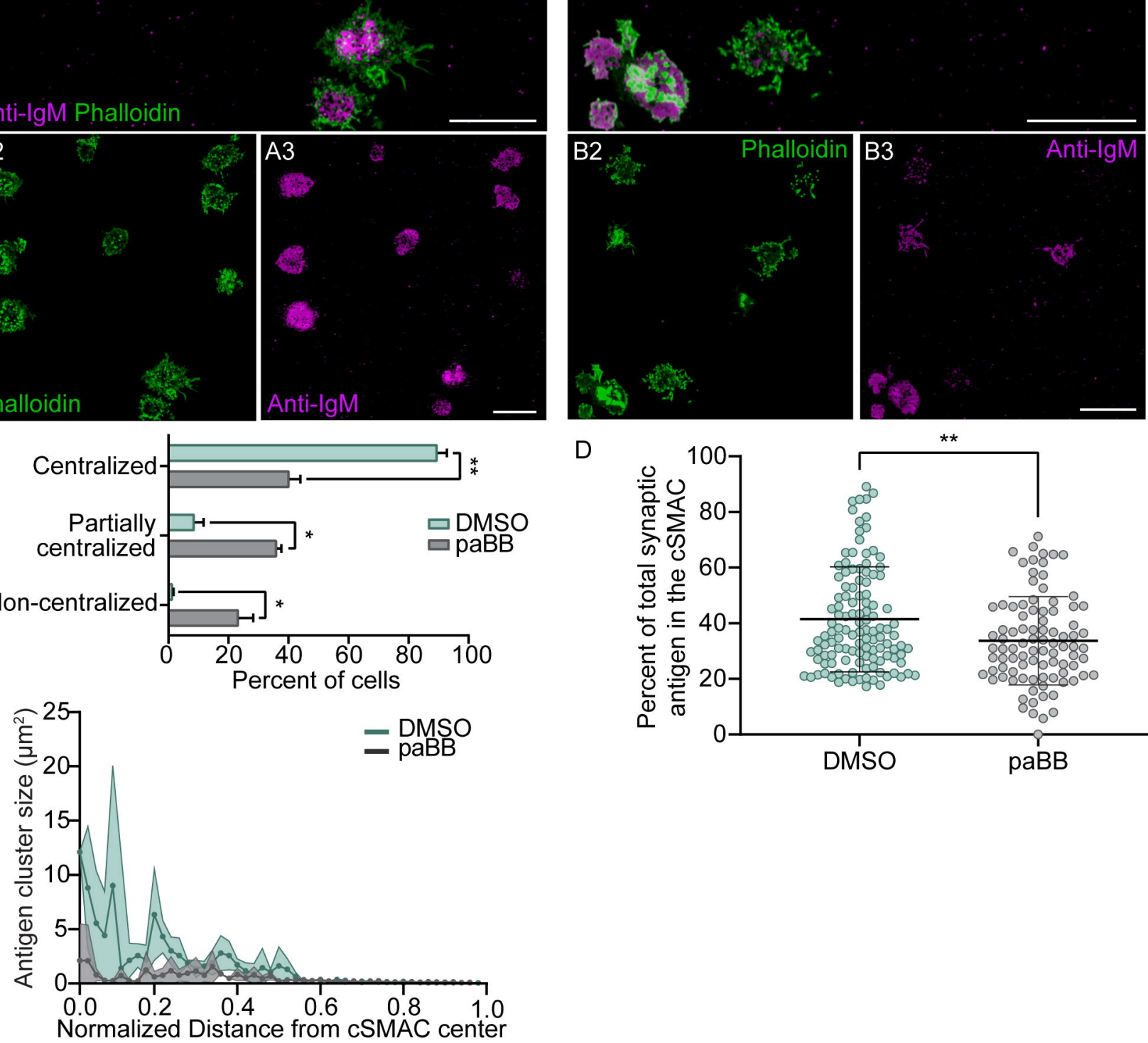

D

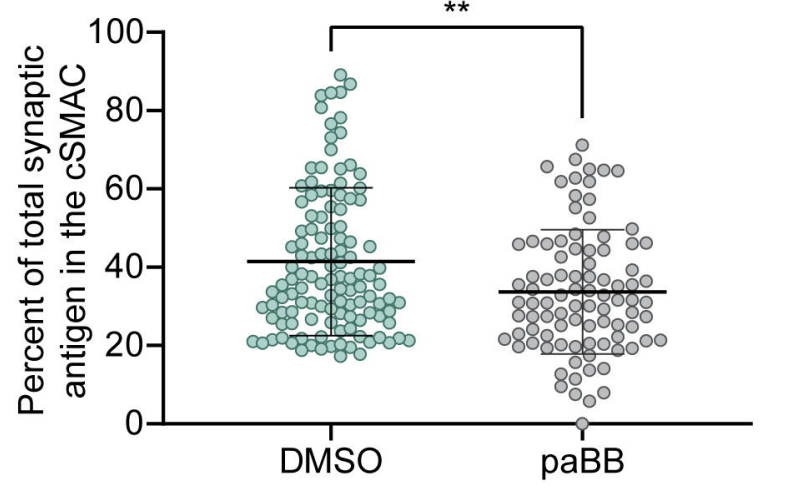


Figure 6 - figure supplement 1

A

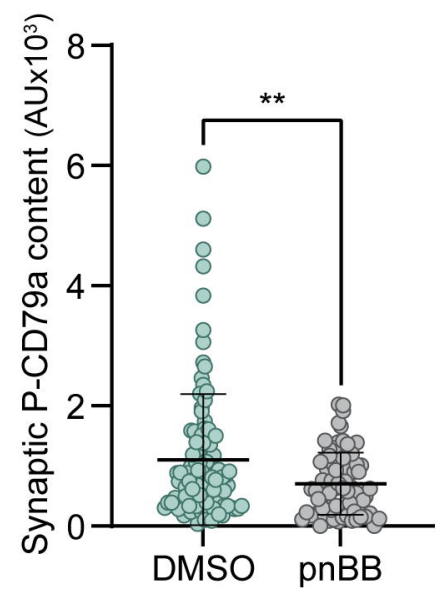

C

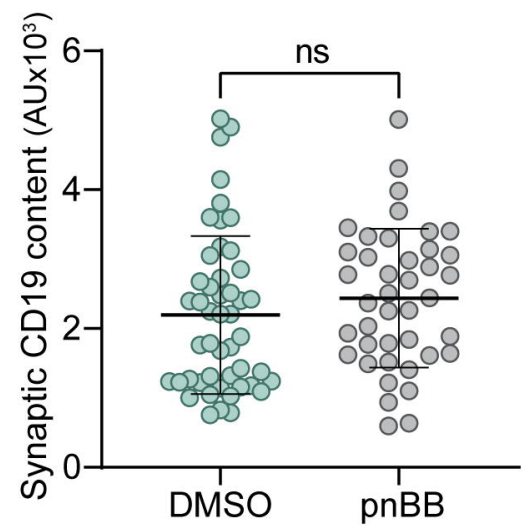

B

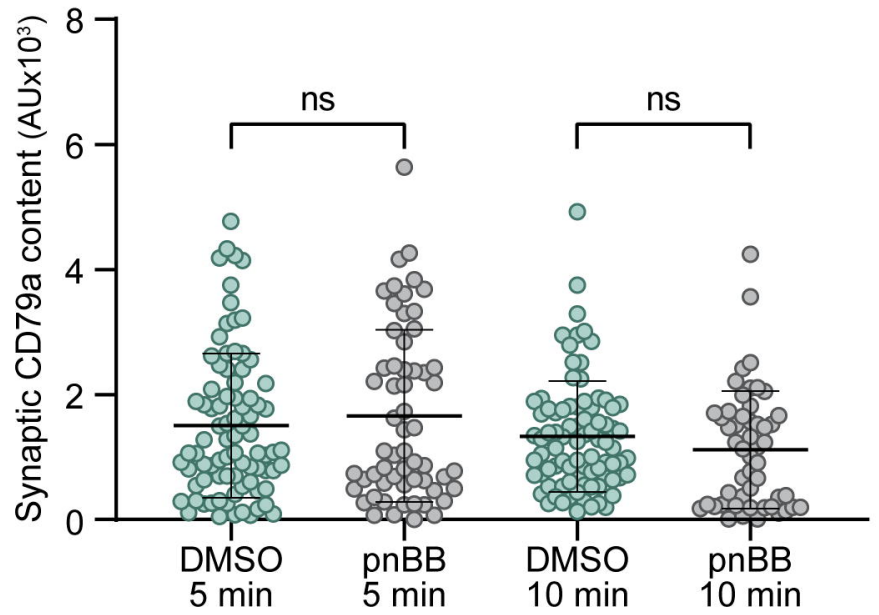




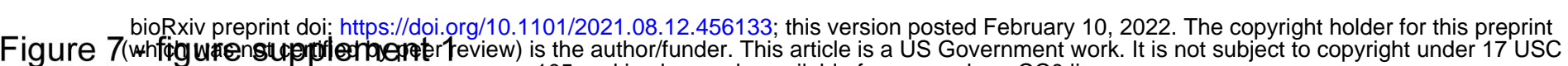
105 and is also made available for use under a CCO license.

\section{Centralized clusters}

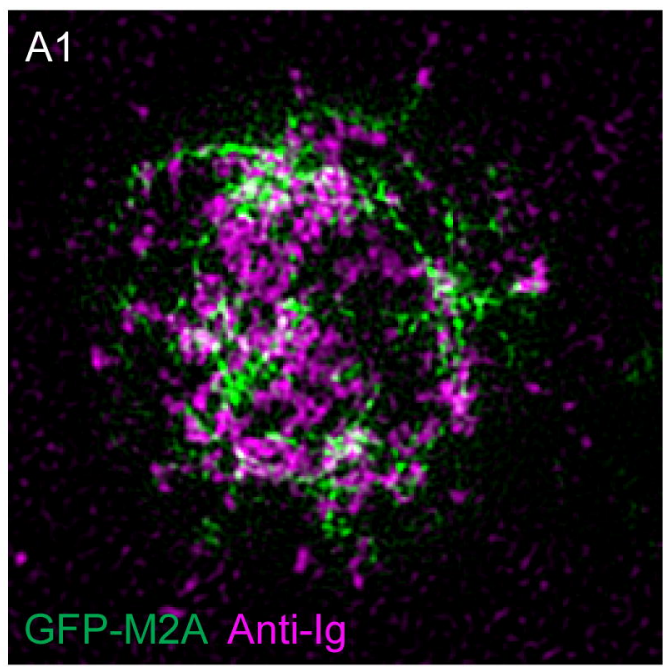

Microclusters

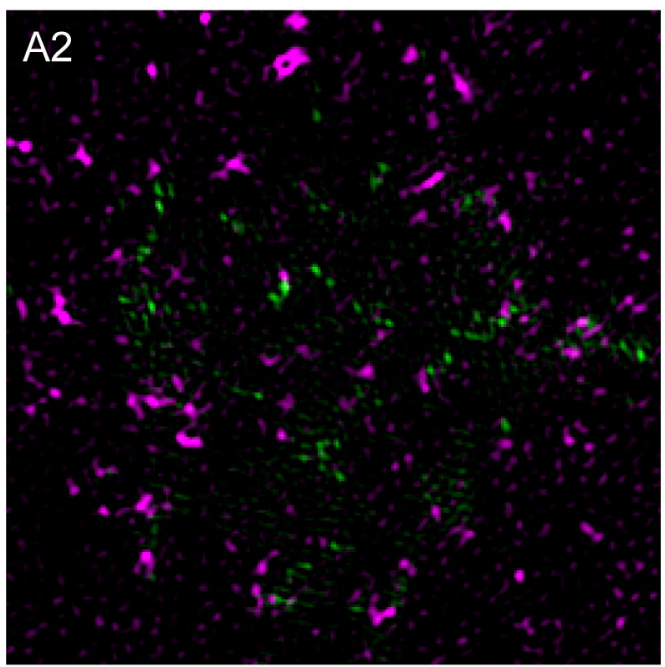

Peripheral clusters

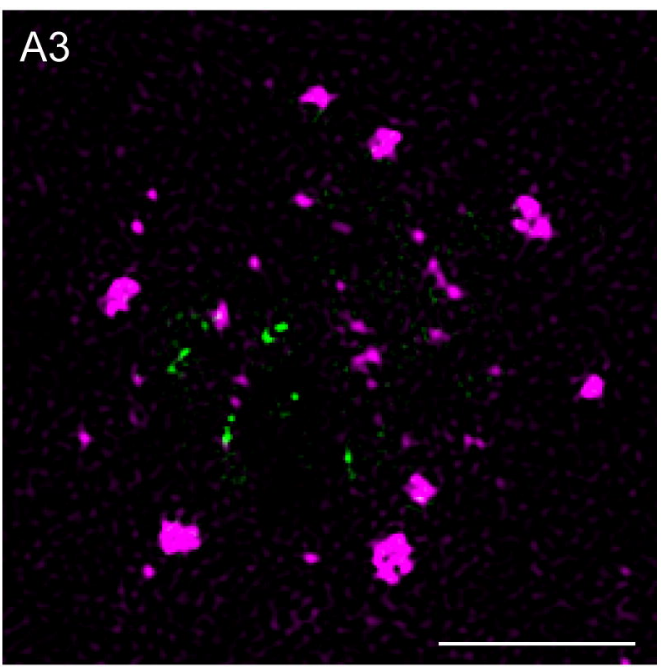

